\title{
Differential Contribution of V0 Interneurons to Execution of Rhythmic and Nonrhythmic Motor Behaviors
}

\author{
${ }^{\circledR}$ Pavel V. Zelenin, ${ }^{1 *}$ Manideep G. Vemula, ${ }^{1 *}$ Vladimir F. Lyalka, ${ }^{1}$ Ole Kiehn, ${ }^{1,2}{ }^{\oplus}$ Adolfo E. Talpalar, ${ }^{1 \dagger}$ and \\ Tatiana G. Deliagina ${ }^{1 \dagger}$ \\ ${ }^{1}$ Department of Neuroscience, Karolinska Institute, SE-17177 Stockholm, Sweden, and ${ }^{2}$ Department of Neuroscience, Faculty of Health and Medical \\ Sciences, University of Copenhagen, 2200-DK Copenhagen, Denmark
}

Locomotion, scratching, and stabilization of the body orientation in space are basic motor functions which are critically important for animal survival. Their execution requires coordinated activity of muscles located in the left and right halves of the body. Commissural interneurons (CINs) are critical elements of the neuronal networks underlying the left-right motor coordination. V0 interneurons (characterized by the early expression of the transcription factor Dbxl) contain a major class of CINs in the spinal cord (excitatory, $\mathrm{V}_{\mathrm{V}}$; inhibitory, $\mathrm{V} 0_{\mathrm{D}}$ ), and a small subpopulation of excitatory ipsilaterally projecting interneurons. The role of V0 CINs in left-right coordination during forward locomotion was demonstrated earlier. Here, to reveal the role of glutamatergic V0 and other V0 subpopulations in control of backward locomotion, scratching, righting behavior, and postural corrections, kinematics of these movements performed by wild-type mice and knock-out mice with glutamatergic V0 or all V0 interneurons ablated were compared. Our results suggest that the functional effect of excitatory V0 neurons during backward locomotion and scratching is inhibitory, and that the execution of scratching involves active inhibition of the contralateral scratching central pattern generator mediated by excitatory V0 neurons. By contrast, other V0 subpopulations are elements of spinal networks generating postural corrections. Finally, all V0 subpopulations contribute to the generation of righting behavior. We found that different V0 subpopulations determine left-right coordination in the anterior and posterior parts of the body during a particular behavior. Our study shows a differential contribution of V0 subpopulations to diverse motor acts that provides new insight to organization of motor circuits.

Key words: commissural interneurons; locomotion; mice; networks; posture; scratching

Significance Statement

Commissural interneurons with their axons crossing the midline of the nervous system are critical elements of the neuronal networks underlying the left-right motor coordination. For the majority of motor behaviors, the neuronal mechanisms underlying left-right coordination are unknown. Here, we demonstrate the functional role of excitatory V0 neurons and other subpopulations of $\mathrm{V} 0$ interneurons in control of a number of basic motor behaviors-backward locomotion, scratching, righting behavior, and postural corrections-which are critically important for animal survival. We have shown that different subpopulations of V0 neurons determine left-right coordination in the context of different behaviors as well as in the anterior and posterior parts of the body during a particular behavior.

Received July 29, 2020; revised Feb. 16, 2021; accepted Feb. 17, 2021.

Author contributions: P.V.Z. and T.G.D. designed research; 0.K. provided animal models; P.V.Z., M.G.V., V.F.L., A.E.T., and T.G.D. performed research; P.V.Z., M.G.V., V.F.L., and T.G.D. analyzed data; O.K., A.E.T., and T.G.D. wrote the paper.

*P.V.Z. and M.G.V. contributed equally to this work.

${ }^{\dagger}$ A.E.T. and T.G.D. contributed equally to this work

This work was supported by the Swedish Research Council (Grant 2017-02944) and KI fonder (Grant 201802081) to T.G.D.; the Swedish Research Council (Grant 21076) to P.V.Z.; and the Swedish Research Council (Grant 2018-02403), National Institutes of Health (Grant 5R01-NS-090919), and the Novo Nordisk Laureate Program (Grant NNF150C0014186) to 0.K. We thank Alessandra Pierani for providing the Dbx-DTA mouse. We also thank T.I. Talpalar for help in determining the phenotypes of the animals.

The authors declare no competing financial interests.

Correspondence should be addressed to Tatiana G. Deliagina at Tatiana.Deliagina@ki.se or Adolfo E. Talpalar at Adolfo.Talpalar @gmail.com.

https://doi.org/10.1523/JNEUROSCI.1979-20.2021

Copyright $\odot 2021$ the authors

\section{Introduction}

Commissural interneurons (CINs) are critical elements of the neuronal networks underlying the left-right coordination required for most types of motor behaviors. Early electrophysiological and morphologic studies in cats and newborn rodents have demonstrated that CINs constitute a large and diverse group of neurons. Populations of CINs differ in their locations in the spinal cord gray matter, in their projection patterns and postsynaptic targets, in their afferent and supraspinal inputs, as well as in their transmitter phenotypes (Harrison et al., 1986; Jankowska and Noga, 1990; Lu et al., 2001; Butt et al., 2002; Stokke et al., 2002; Bannatyne et al., 2003, 2006; Birinyi et al., 2003; Butt and Kiehn, 2003; Kiehn and Butt, 2003; Matsuyama et 
al., 2004a,b, 2006; Nissen et al., 2005; Jankowska et al., 2005a,b,c; Wéber et al., 2007; Restrepo et al., 2009). This diversity indicates that specific populations of CINs may contribute to left-right coordination during different movements.

Recently in mice, interneurons have been divided into populations according to the specific molecular markers that they express (Jessell, 2000; Moran-Rivard et al., 2001; Pierani et al., 2001; Lanuza et al., 2004; Zhang et al., 2008; Goulding, 2009; Rabe et al., 2009; Kiehn, 2011; Borowska et al., 2013; Talpalar et al., 2013; Haque et al., 2018). One of these populations, the V0 interneurons (characterized by the early expression of the transcription factor Dbx1) contains a major class of CINs in the ventral spinal cord (Pierani et al., 2001; Lanuza et al., 2004). The V0 population contains two subpopulations of CINs-the excitatory (glutamatergic) V0 ventral $\left(\mathrm{V}_{\mathrm{V}}\right)$ and the inhibitory (GABAergic and glycinergic) V0 dorsal ( $\mathrm{VO}_{\mathrm{D}}$; Moran-Rivard et al., 2001; Pierani et al., 2001; Lanuza et al., 2004; Talpalar et al., 2013; Griener et al., 2015). In addition, it contains other $\mathrm{V} 0_{\mathrm{V}}$ neurons in the brainstem mainly involved in the control of respiration (Gray, 2013; Ruangkittisakul et al., 2014), and two small subpopulations ( $\sim 2 \%$ each) of ipsilaterally projecting excitatory neurons-cholinergic $\mathrm{V} 0$ neurons $\left(\mathrm{V0}_{\mathrm{C}}\right)$ that constitute the C-boutons on motor neurons (Zagoraiou et al., 2009) and glutamatergic V0 spinal neurons $\left(\mathrm{V}_{\mathrm{G}}\right)$ with unknown specific projections (Zagoraiou et al., 2009).

The functional role of V0 CINs in control of left-right coordination during locomotor-like activity in vitro (Lanuza et al., 2004; Talpalar et al., 2013) and forward (FW) locomotion in vivo (Talpalar et al., 2013) has been investigated. It was demonstrated that the inhibitory $\mathrm{V} 0_{\mathrm{D}}$ neurons are responsible for left-right hindlimb alternation at low locomotor frequencies, while the excitatory $\mathrm{V} 0_{\mathrm{V}}$ neurons are responsible for execution of hindlimb alternation at high locomotor frequencies (Talpalar et al., 2013). These two locomotor frequencies correspond to walk and trot, respectively (Bellardita and Kiehn, 2015). The distinct roles of two subpopulations of V0 CINs in control of FW locomotion, as well as their distinct phenotypes (excitatory $\mathrm{V}_{\mathrm{V}}$ and inhibitory $\mathrm{V}_{\mathrm{D}}$ ) suggest that they may contribute differently to the control of other motor behaviors.

Here we elucidated the functional role of different subpopulations of V0 neurons in control of a number of basic motor behaviors: backward (BW) locomotion, scratching, righting behavior, and postural corrections. These behaviors require left-right coordination mediated by yet unknown neuronal mechanisms. BW locomotion and scratching are both rhythmic movements, but BW locomotion involves leftright limb alternation (Buford et al., 1990; Vemula et al., 2019), while scratching movements are performed by only one hindlimb (Deliagina et al., 1975; Kuhta and Smith, 1990; Inagaki et al., 2001). However, strong reciprocal inhibition between the left and right scratching networks has been suggested (Deliagina, 1977). The righting behavior (Magnus, 1924) as well as postural corrections caused by tilting of the support surface (Beloozerova et al., 2003; Deliagina et al., 2006) are essential for the control of posture. The righting behavior requires coordinated activity of left and right muscles of the trunk and limbs, while postural corrections are performed by reciprocal flexion-extension movements of the left and right limbs. Our study demonstrates that the integrity of V0 neurons is essential for normal execution of all four studied motor behaviors. However, specific subpopulations of V0 neurons differentially contribute to these different motor behaviors, as well as to different aspects of the same behavior.

\section{Materials and Methods}

Experiments were performed on $13 \mathrm{Dbx1}^{\mathrm{DTA}}$; Hoxb8 $8^{\mathrm{Cre}}$ mice (V0-KO mice) and $9 D b x 1^{D T A} ; V_{\text {glut }}{ }^{\text {Cre }}$ mice $\left(\mathrm{V0}_{\mathrm{Glut}}-\mathrm{KO}\right.$ mice), as well as on their 14 wild-type littermates (control mice). The knock-out (KO) and control mice were of both sex (weight, 18-30 g; age, 5-10 weeks). They were housed in standard cages with food and water ad libitum in a $12 \mathrm{~h}$ light/dark cycle. All experiments were conducted with the approval of the local ethical committee (Norra Djurförsöksetiska Nämnden) in Stockholm and followed the European Community Council Directive (2010/63EU) and the National Institutes of Health Guide for the Care and Use of Laboratory Animals.

Mice. All genetically modified animals were derived from C57 black background strains. Ablation of all spinal V0 neurons was obtained by crossing homozygote Dbx1-lox-stop-lox-DTA mice ( $D b \times 1^{D T A}$; Talpalar et al., 2013) with heterozygote Hoxb8 ${ }^{\text {Cre }}$ mice (Witschi et al., 2010), which resulted in mice that are devoid of Dbx1-derived cells in the spinal cord caudal to cervical root 4 (C4). Similarly, ablation of glutamatergic $\mathrm{V} 0$ neurons $\left(\mathrm{V}_{\mathrm{Glut}}\right)$ was obtained by crossing homozygote $D b \times 1^{D T A}$ mice with heterozygote $\operatorname{Vglut} 2^{\text {Cre }}$ (Borgius et al., 2010) mice, which were devoid of Vglut2-expressing V0 neurons (Talpalar et al., 2013). The Vglut2 ${ }^{\text {Cre }}$ animals are BAC transgenic and express Cre in Vglut2-positive neurons in the spinal cord and various regions of the brainstem, but not in Dbx1-positive progenitors of the respiratory centers (Borgius et al., 2010; Talpalar et al., 2013). The use of these Vglut $2^{\text {Cre }}$ mice allows the generation of viable mice devoid of $\mathrm{V}_{\text {Glut }}$ neurons in the spinal cord, which can survive until the adult age. All animals were genotyped with specific primers.

An issue about the chronic ablation of V0 neurons that we consider here is that the early ablation might lead to compensatory or adaptive changes in the network structure leading to a motor output not directly related to the V0 function. This concern could potentially be minimized by instead using acute manipulation of V0 neurons. However, such experiments are yet impossible because of the extended segmental architecture of the cord makes spinal neurons inaccessible for optogenetic manipulation in vivo, while chemogenetic manipulation [designer receptor exclusively activated by designer drugs (DREADD)] requires three recombination systems-one for the V0 (Dbx1); one for V0 subset (Vglut2 or Vgat); and one for CNS location (Hoxb8), a mouse technology not yet available. We have therefore used chronic ablation similar to previous studies of FW locomotion where there was exceptional correlation between adult in vivo and newborn in vitro models (Gosgnach et al., 2006; Crone et al., 2008, 2009; Talpalar et al., 2011, 2013; Bouvier et al., 2015), suggesting little interference from compensatory plastic changes if any to motor output. Unlike those studies, the present behavioral sets have no in vitro models and therefore required the generation of longliving phenotypes. We acknowledge that we cannot completely exclude compensatory changes but assume that they do not affect the principal organization of the networks underlying the studied behaviors.

Surgical procedures. All surgical procedures were performed under general anesthesia and aseptic conditions. General anesthesia consisted of ketamine $(75 \mathrm{mg} / \mathrm{kg})$ in combination with medetomidine $(1 \mathrm{mg} / \mathrm{kg})$ given intraperitoneally.

EMG electrodes were implanted in 13 animals $\left(3 \mathrm{~V}_{\text {Glut }}-\mathrm{KOs}, 3 \mathrm{V0}\right.$ $\mathrm{KOs}, 4 \mathrm{V0} 0_{\text {Glut }}$-KO-controls, and $3 \mathrm{V0}-\mathrm{KO}$-controls). In each animal, bipolar EMG electrodes (flexible stainless steel, Teflon-insulated wires; catalog \#AS631, Cooner Wire) were implanted bilaterally into tibialis anterior (Tib; ankle flexor) or gastrocnemius lateralis (Gast; ankle extensor). The method of implantation of EMG electrodes was similar to that described previously (Takeoka et al., 2014). In short, recording electrodes and a common ground wire were fabricated by removing a small $(0.5 \mathrm{~mm}$ notch $)$ and a large $(1 \mathrm{~cm})$ part of Teflon from the distal extremity of the wire, respectively. The wires were led subcutaneously and connected to a percutaneous connector (Omnetics Connector/Amphenol) cemented by dental adhesive (OptiBond, Kerr) to the skull of the mouse. The weight of the connector was $\sim 1$ g. A ground wire was inserted subcutaneously over the shoulder region. The proper location of the electrodes was verified postmortem.

For analgesia, buprenorphine $(0.1 \mathrm{mg} / \mathrm{kg})$ was given subcutaneously postoperatively twice daily for $2 \mathrm{~d}$ to all animals subjected to surgery. Experiments started 1-2 d after the surgery. 
Experimental designs. Both mutant mice and their WT littermates performed four basic motor behaviors: backward locomotion, scratching, righting, and postural corrections on a tilting platform.

BW locomotion was performed in a tunnel setup (Fig. 1A) described previously (Vemula et al., 2019). It was made of transparent Plexiglas and imitated the narrow tunnels of the burrows in which mice live in nature. The setup consisted of a narrow tunnel (length, $50 \mathrm{~cm}$; height, $4 \mathrm{~cm}$; width, $2.5-3.5 \mathrm{~cm})$ with a small box $(7 \times 7 \times 4 \mathrm{~cm}$ each $)$ at each end of the tunnel. Each box had a removable top and a door that closed the entrance to the tunnel. One of the side walls of the tunnel was movable so that the width of the tunnel could be adjusted to the size of a mouse in such a way that the animal could easily walk in the tunnel straight BW but could not turn around. The animal was placed in the entrance box through the removable top and the top was closed, then the door to the tunnel was opened and the animal performed locomotion. When the mouse reached the end of the tunnel, it performed BW locomotion until it reached the door closing the tunnel entrance. Usually, the animal spontaneously exhibited three to four sequential episodes of FW and BW locomotion. Each episode of BW walking in the tunnel consisted of five to nine steps.

To evoke scratching (Fig. $1 B, C$ ), a drop of a watercolor paint was placed on the fur located on the base of the external or internal surface of the pinna. Then, the animal was positioned in the box (length, $10 \mathrm{~cm}$; height, $18 \mathrm{~cm}$; width, $10 \mathrm{~cm}$ ) without a roof made of transparent Plexiglas. Usually, when the paint on the pinna became solid, spontaneous episodes of scratching were observed. In rare cases, when the paint did not evoke spontaneous episodes of scratching, additional light mechanical stimulation of the painted spot (stroking by a thin blunt rod) evoked a scratching episode. After recording four to six episodes of scratching, the paint was removed.

To evoke righting behavior (Fig. $1 E$ ), a mouse was positioned on its back on a horizontal surface. The animal was then released so it could assume the normal body orientation characteristic for standing.

To evoke postural corrections, the mouse was positioned on the tilting platform $(12 \times 12 \mathrm{~cm})$ with the sagittal plane of the animal aligned to the axis of the platform rotation (Fig. $1 F$ ). The platform was made of transparent Plexiglas, and the surface of the platform was covered with transparent SYLGARD to increase friction and prevent sliding of the animal during tilts. The platform with the animal was tilted periodically in the frontal (transverse) plane of the animal (Fig. 1G, roll tilt $\alpha$ ) with the amplitude of $\pm 20^{\circ}$. A trapezoid tilt trajectory with the transitions between extreme positions lasting for $\sim 0.5-1 \mathrm{~s}$, and each position maintained for $\sim 1-1.5 \mathrm{~s}$ was used (Fig. $1 G, H$ ). The tilt angle of the platform was monitored with a mechanical sensor. It was necessary to habituate animals to the tilting platform and to train them to stand still during tilts. For this purpose, the animal was positioned on the tilting platform, and tilts with increasing amplitude were applied. If the animal started to walk, it was returned to the initial standing position by the experimenter. Usually, a 20 min session of such training performed during 2-3 d was sufficient to evoke episodes, in which the mouse maintained standing posture with its sagittal plane aligned to the axis of the platform rotation leading to postural corrections in response to five to seven sequential tilt cycles.

To characterize the kinematics of fast movements performed during locomotion, scratching, and righting, high-speed video recording (100 frames/s) was used, while relatively slow postural corrections were video recorded with lower speed (50 frames/s). Simultaneously, the side and the below (by means of a mirror) views of the animals were recorded during locomotion (Fig. $1 A$ ), scratching (Fig. $1 B, C$ ), and righting (Fig. $1 E$ ), while during postural corrections (Fig. $1 F$ ) the back view and the bottom view of the animal were recorded.

The hindlimbs and trunk of the animal were shaved, and markers were drawn on the skin above the metatarsophalangeal and ankle joints, as well as on the spine at the level of the rostral end of the pelvis. The video camera was positioned at a distance of $\sim 2 \mathrm{~m}$ from the mouse.

Recording and data analysis. Signals from the EMG electrodes, and from the tilting platform position sensor were amplified, digitized with a sampling frequency of $5 \mathrm{kHz}$ (EMGs) and $1 \mathrm{kHz}$ (sensor), and recorded on a computer disk using a data acquisition and analysis system
(Power1401/Spike2, Cambridge Electronic Design). Recordings of EMGs and platform tilts were synchronized with video recordings.

The video recordings were analyzed frame by frame. To compare interlimb coordination, as well as the structure of locomotor cycle in $\mathrm{KO}$ and control mice, the moments of the paw liftoff and touchdown were determined. The period between these moments was considered as the swing phase and the rest of the cycle as the stance phase.

For analysis of coordination between the right and left limbs of the same girdle, one limb was selected as a reference limb, its step cycle was normalized to 1.0 (the onset of swing was taken as the cycle onset), and the phases of paw-off moments of the contralateral limb were calculated in the reference cycles. The difference between the swing-onset phases of two limbs was termed the "phase shift between limbs." The mean ( \pm SD) values of the phase shift between forelimbs, as well as between hindlimbs observed in $\mathrm{V0}_{\mathrm{Glut}}-\mathrm{KOs}, \mathrm{V} 0-\mathrm{KOs}$, and control mice during locomotion were calculated using circular statistics methods (Batschelet, 1981).

To characterize the coordination between scratching movements of the left and right hindlimbs in $\mathrm{V0}-\mathrm{KO}$ and $\mathrm{V0}_{\mathrm{Glut}}-\mathrm{KO}$ mice, the hindlimb ipsilateral to the stimulation side was selected as the reference limb. The period between the two sequential most rostral limb positions was considered a scratching cycle. The scratching cycle of the reference limb was normalized to 1.0 (the most rostral limb position was taken as the cycle onset), and the phase of the moment when the contralateral limb assumed the most rostral position, was calculated in the reference cycle. These phases (representing phase shifts between limbs) then were averaged across the cycles of the episode using circular statistics.

To compare scratching movements of the hindlimb ipsilateral to the stimulation side with those performed by the contralateral hindlimb in $\mathrm{KO}$ mice, as well as to compare scratching movements in KO mice with those observed in control animals, two measures were made. First, in each scratching episode the amplitude of the limb protraction toward the stimulation point, which preceded the rhythmical movements (Fig. $1 C, P)$, was measured by using the bottom view. Second, in each scratching cycle of the episode, the amplitude of the movement in rostrocaudal and mediolateral directions was measured by using the bottom view (Fig. $1 D$, bottom, R-C, M-L, respectively) and in the dorsoventral direction by using the side view (Fig. $1 D$, top, D-V). Since mice differed in size, the amplitudes were normalized to the body length measured postmortem.

To compare the efficacy of postural corrections, we calculated the coefficient of postural stabilization $\mathrm{K}_{\mathrm{STAB}}=1-\beta / \alpha$, where $\beta$ is the hindquarters tilt, and $\alpha$ is the platform tilt (Fig. $1 F$ ). The dorsoventral axis of the hindquarters was determined as a line connecting the marker on the spine with the axis of rotation. With perfect stabilization, $\mathrm{K}_{\mathrm{STAB}}=$ 1; with no stabilization, $\mathrm{K}_{\mathrm{STAB}}=0$.

Statistical analysis. Sample size was not estimated a priori to obtain a given power. Mice were randomly allocated to different groups for the in vivo experiments using a block design. Data sampling and analysis were not blinded. All quantitative data in this study are presented as the mean $\pm \mathrm{SD}$. Mean values were calculated as averages of the mean from each animal. $N$ represents biological replications, while $n$ represents technical replications. The Student's $t$ test (two-tailed) was used to characterize statistical significance when comparing different means; the significance level was set at $p=0.05$.

\section{Results}

To reveal the role of $\mathrm{V} 0_{\mathrm{Glut}}$ and other $\mathrm{V} 0$ subpopulations in the control of the four motor behaviors, we used V0-KO mice with all V0 subpopulations ablated in the spinal cord only (caudally to $\mathrm{C} 4$ segment), and $\mathrm{V} 0_{\mathrm{Glut}}-\mathrm{KO}$ mice with $\mathrm{V}_{\mathrm{Glut}}$ neurons ablated in the entire CNS (Talpalar et al., 2013). We were unable to target the $\mathrm{V0}_{\mathrm{D}} \mathrm{CINs}$ directly because ablation of these neurons caused perinatal death (Talpalar et al., 2013), possibly because it affects brainstem functions. We, therefore, compared the results form $\mathrm{V}_{\text {Glut }}-\mathrm{KO}$ and $\mathrm{V0}-\mathrm{KO}$ mice to deduct the possible contribution of $\mathrm{V} 0_{\mathrm{D}} \mathrm{CIN}$ and $\mathrm{V} 0_{\mathrm{C}}$ subpopulations by subtraction. 

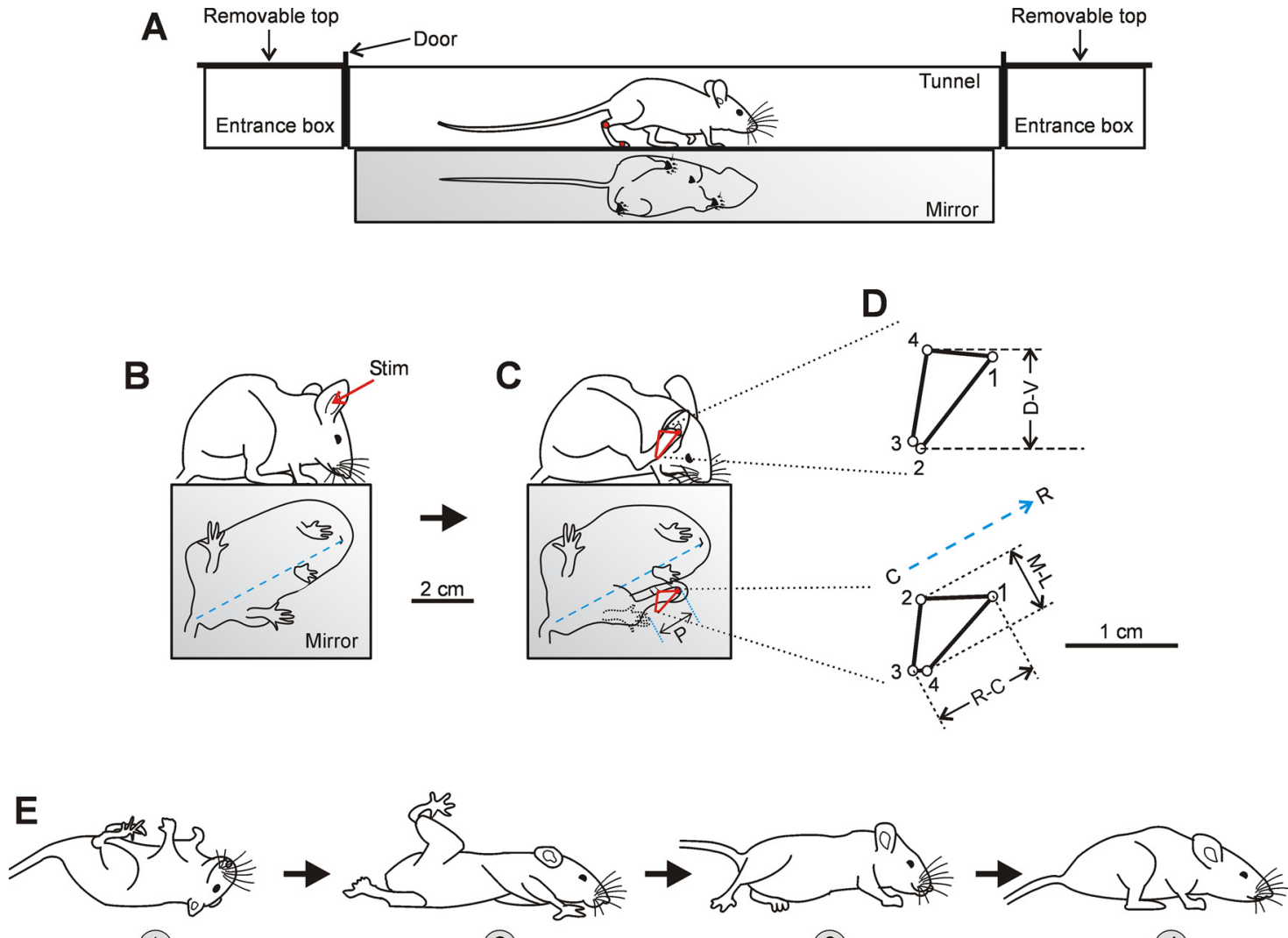

(1)

(2)

Stage 1

Stage 2

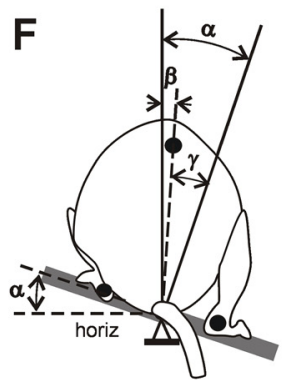

G

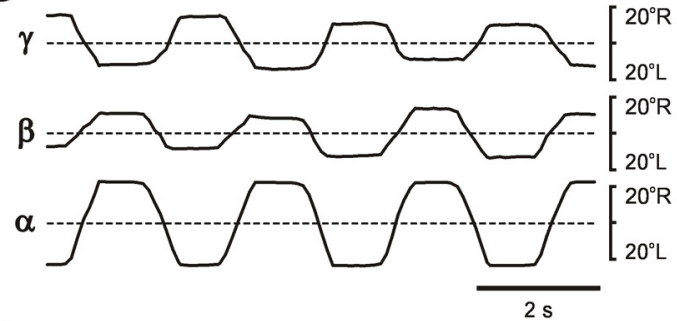

H

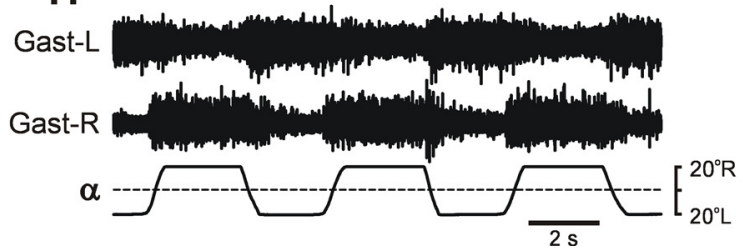

Figure 1. Experimental designs. $\boldsymbol{A}$, Tunnel setup for recording of locomotion. $\boldsymbol{B}, \boldsymbol{C}$, The side and the bottom view of a control mouse just before $(\boldsymbol{B})$ and during $(\boldsymbol{C})$ scratching caused by mechanical stimulation of the pinna (Stim; in $\boldsymbol{B})$. In $\boldsymbol{C}, \mathrm{P}$, the amplitude of the limb protraction [excursion of the hindlimb from initial position (indicated by dotted line) to the stimulation point] that preceded rhythmic scratching movements. $\boldsymbol{D}$, Side (top) and bottom (bottom) views of the distal point trajectory of the hindlimb (C, red line) during one scratching cycle. Time between points $10 \mathrm{~ms}$. D-V, excursion of the limb in the dorsoventral direction; M-L, excursion of the limb in the mediolateral direction; and R-C, excursion of the limb in the rostrocaudal direction. Blue dashed line is the orientation of the body axis estimated from the view from below as a line connecting the mouth with the base of tail. Rostral end (R) and caudal end (C) of the body axis. $\boldsymbol{E}$, Righting behavior. Sequential positions of the mouse (1-4) that, starting from an upside-down position, acquired a dorsal side-up position. Two stages of the righting (stage 1 and stage 2) are indicated. $\boldsymbol{F}$, Setup for testing postural corrections. The animal performed postural corrections in response to the lateral tilts of the supporting platform. The rear view of the animal was used to measure the platform tilt $(\alpha)$, and the tilt of the caudal part of the trunk in relation to vertical $(\beta)$ and in relation to the platform $(\gamma)$. The dorsoventral trunk axis was determined as a line connecting the marker positioned on the spine at the level of the rostral pelvis (black circle) and the axis of rotation. $\mathbf{G}$, Tilts of the platform $(\alpha)$ caused lateral displacement of the trunk in relation to the platform $(\gamma)$ and to external space $(\beta)$. $\boldsymbol{H}$, Activity of the left Gast (Gast-L) and right Gast (Gast-R) recorded in control mice during postural corrections caused by the platform tilts. 
The majority of V0-KO mice had postural asymmetry in contrast to $\mathrm{V}_{\mathrm{Glut}}-\mathrm{KO}$ mice and wild-type littermates (control mice) which had a symmetrical body posture (for details see subsection Ablation of V0 neurons decreases efficacy of postural corrections). We did not find any significant difference between results obtained in symmetrical and asymmetrical V0-KO mice, and they were therefore pooled. Similarly, if a difference between control data obtained in wild-type littermates of $\mathrm{V}_{\mathrm{Glut}}-\mathrm{KO}$ and $\mathrm{V} 0-\mathrm{KO}$ mice was insignificant, they were pooled for analysis.

\section{Ablation of V0 neurons changes characteristics of BW locomotion}

$\mathrm{V0}_{\mathrm{Glut}}-\mathrm{KO}$ and $\mathrm{V0}-\mathrm{KO}$ mice, as well as control mice performed FW and BW locomotion in a narrow tunnel (Fig. $1 A$; for details, see Materials and Methods). FW locomotion in $\mathrm{V}_{\mathrm{Glut}^{-}} \mathrm{KO}$ and $\mathrm{V} 0-\mathrm{KO}$ mice has been characterized previously (Talpalar et al., 2013; Bellardita and Kiehn, 2015). Here we concentrated our analysis on BW locomotion. To reveal changes in the operation of locomotor mechanisms caused by the ablation of different populations of V0 neurons, we compared general characteristics of locomotor movements, as well as interlimb coordination observed in $\mathrm{V}_{\mathrm{Glut}}-\mathrm{KO}, \mathrm{V0}-\mathrm{KO}$, and control mice.

\section{General characteristics of locomotor movements}

Animals were not trained to perform BW locomotion with a definite speed. Thus, the speed was entirely internally generated. The general characteristics of BW locomotor movements obtained in the present study (locomotor speed, frequency of locomotor movements, step amplitude, duration of the stance, and swing phases) in wild-type mice (Fig. $2 A, B)$ were similar to those reported earlier for wild-type mice performing BW locomotion in similar environmental conditions (Vemula et al., 2019).

The average locomotor speed during BW locomotion in both $\mathrm{V0}_{\mathrm{Glut}}-\mathrm{KO}$ and $\mathrm{V0}-\mathrm{KO}$ mice was in the same range as that observed in control mice (Fig. $2 \mathrm{~A}$ ). In $\mathrm{V0}_{\mathrm{Glut}}$ - $\mathrm{KO}$ mice, this correspondence was caused by similarity in the step amplitude, frequency of locomotor movements, and the duration of the stance and swing phases with those observed in control mice (Fig. $2 A, B)$. In contrast, in $\mathrm{V} 0-\mathrm{KO}$ mice the correspondence in speed to control mice was caused by specific changes in locomotor parameters. There was a twofold decrease in the average step amplitude, accompanied by a twofold increase in the frequency of locomotor movements compared with those observed in control mice (unpaired $t$ test, $t_{(9)}=3.93, p=0.003$, and $t_{(4)}=-4.91$, $p=0.008$, respectively; Fig. $2 A, B$, respectively). The dramatic increase in the frequency of locomotor movements in $\mathrm{V} 0-\mathrm{KO}$ mice reflected in a decrease in the duration of the locomotor cycle $(0.09 \pm 0.01 \mathrm{~s}$ for $\mathrm{V} 0-\mathrm{KO}$ mice vs $0.15 \pm 0.02 \mathrm{~s}$ for control mice; $N=7, n=78$ and $N=4, n=43$, respectively; unpaired $t$ test, $t_{(9)}=5.80, p=2.6 \times 10^{-4}$ ) was caused mainly by a decrease in the duration of the stance phase, compared with that observed in control mice (unpaired $t$ test, $t_{(8)}=5.36$, $p=0.68 \times 10^{-5}$; Fig. $\left.2 B\right)$.

Thus, in V0-KO mice, the majority of locomotor parameters of BW locomotor movements differed significantly from those observed in control mice, while in $\mathrm{V0}_{\mathrm{Glut}}-\mathrm{KO}$ mice all parameters were similar to those in control mice. By subtraction, these results suggest that at least one of the $\mathrm{V} 0_{\mathrm{D}}$ and $\mathrm{V} 0_{\mathrm{C}}$ subpopulations or both subpopulations (which are absent only in the V0$\mathrm{KO}$ mice) contributed to setting of the main characteristics of locomotor movements during BW locomotion.
$\mathrm{V0}_{\text {Glut }}-\mathrm{KO}$ and $\mathrm{V0}-\mathrm{KO}$ mice, like control mice, showed a strong positive correlation between the cycle duration and the stance duration and a weak dependence of the swing duration on the cycle duration during BW locomotion (Fig. 2C-E). Thus, in both types of $\mathrm{KO}$ mice an increase in the cycle duration of $\mathrm{BW}$ locomotion is caused by prolongation of the stance duration, while the swing duration remains relatively constant.

\section{Interlimb coordination}

Hindlimb coordination. During BW locomotion, the control mice moved hindlimbs in alternation (Fig. $2 F$ ). In contrast, both $\mathrm{V0}_{\mathrm{Glut}}-\mathrm{KO}$ and $\mathrm{V0}-\mathrm{KO}$ mice moved hindlimbs synchronously (Fig. 2G,H).

The hindlimb coordination was quantified using circular plots. Although hindlimb alternation dominated in control animals (the mean value of the phase shift between hindlimbs was close to the 0.5 part of the cycle), hindlimb coordination was rather irregular. It was reflected in a large SD of the mean phase shift $(0.44 \pm 0.21$ part of the cycle; Fig. $2 I)$. In both $\mathrm{V} 0_{\mathrm{Glut}}-\mathrm{KO}$ and $\mathrm{V0}-\mathrm{KO}$ mice, the mean value of the phase shift between hindlimbs was close to 0 (Fig. 2I). These results suggest that the $\mathrm{V} 0_{\mathrm{Glut}}$ subpopulation-which is absent in both $\mathrm{V} 0_{\mathrm{Glut}} \mathrm{KO}$ and $\mathrm{V} 0-\mathrm{KO}$ mice-determines hindlimb alternation during $\mathrm{BW}$ locomotion.

Forelimb coordination. The forelimb coordination in control and $\mathrm{V} 0-\mathrm{KO}$ mice (Fig. 3E) was similar to that observed in hindlimbs (Fig. 2J): forelimbs alternated in control mice and were in synchrony in $\mathrm{V0}-\mathrm{KO}$ mice. But $\mathrm{V0}_{\mathrm{Glut}}-\mathrm{KO}$ mice showed different coordination between forelimbs and between hindlimbs: hindlimbs moved synchronously (Fig. 2I), while forelimbs alternated (Fig. 2J). These results suggest that forelimb alternation cannot be secured during $\mathrm{BW}$ locomotion by the $\mathrm{V} 0_{\text {Glut }}$ subpopulation alone and requires the integrity of at least one or both of the $\mathrm{V} 0_{\mathrm{D}}$ and $\mathrm{V} 0_{\mathrm{C}}$ subpopulations.

\section{Ablation of V0 neurons results in anomalous bilateral scratching}

To evoke scratching reflex, the pinna was mechanically stimulated (Fig. 1B,C; for details, see Materials and Methods). As in other terrestrial quadrupeds (Sherrington, 1906, 1910; Deliagina et al., 1975; Stein, 1983); all control mice $(N=6)$ performed rhythmic scratching movements by one hindlimb ipsilateral to the stimulation side. The scratching behavior consisted of two components (Sherrington, 1906, 1910; Deliagina et al., 1975; Deliagina, 1977; Kuhta and Smith, 1990). First, the postural component is executed. It includes protraction of the ipsilateral (to the side of stimulation) hindlimb to the stimulated area of the skin accompanied by body and neck bending toward the protracting hindlimb (Fig. 1C). Second, the rhythmic component is generated. It is composed of fast alternating flexions and extensions in the ankle, knee, and hip joints that result in the repetitive scratching of the irritated area of the skin. A typical example of side and bottom views of the trajectory of the distal point of the hindlimb during scratching cycle is shown in Figure $1 D$ (top and bottom, respectively).

In contrast to the unilateral scratching observed in control mice (Fig. $3 A$ ), both $\mathrm{V} 0-\mathrm{KO}(N=6)$ and $\mathrm{V} 0_{\mathrm{Glut}}-\mathrm{KO}(N=4)$ mice performed rhythmic scratching movements with both hindlimbs in response to unilateral stimulation (Fig. 3B,C). These bilateral movements were almost synchronous (the mean value of the phase shift between movements of the contralateral and ipsilateral to stimulation side limbs was close to 0 (Fig. 3D). The average frequency of scratching movements in $\mathrm{V} 0-\mathrm{KO}$ mice was 

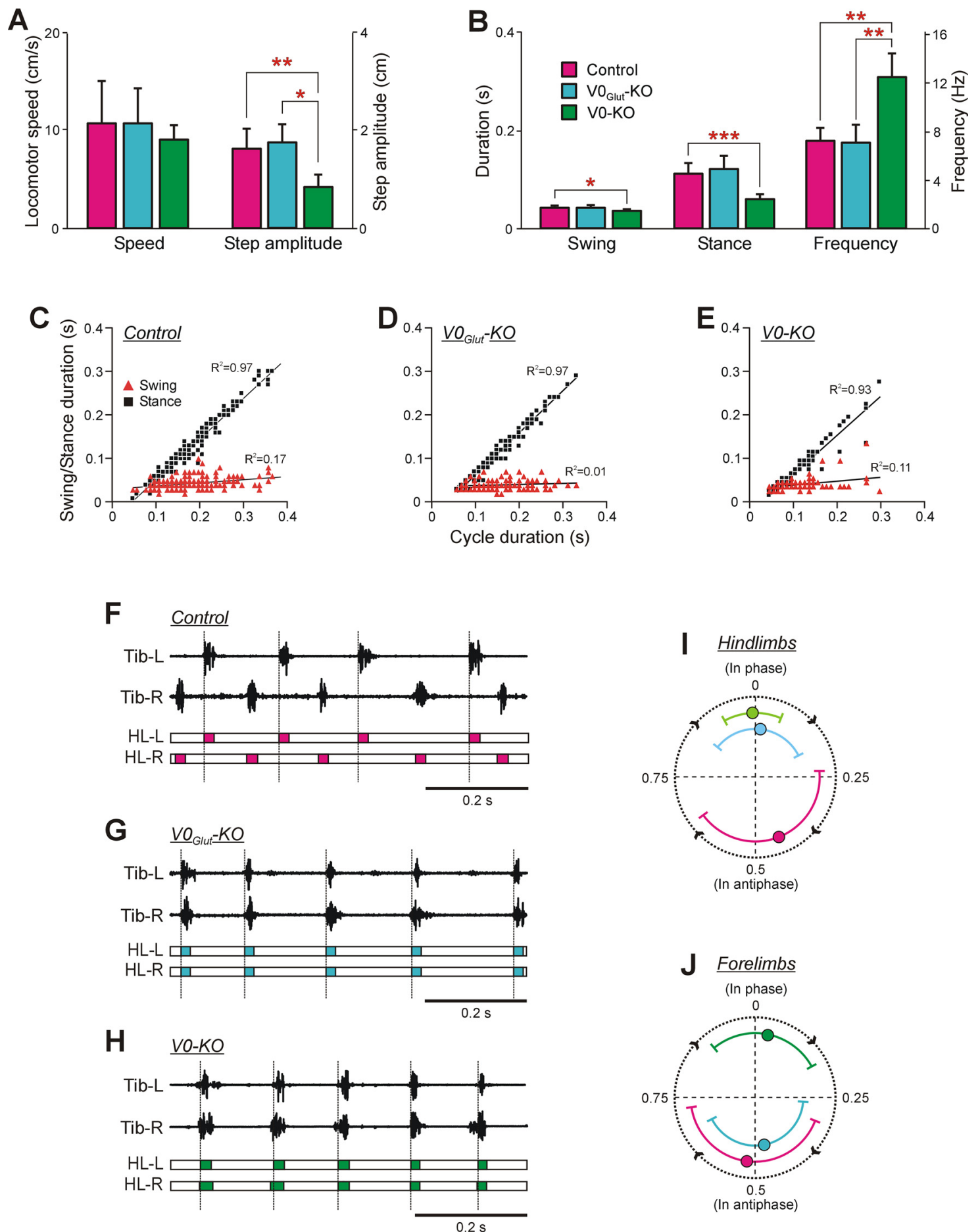

Figure 2. Comparison of $B W$ locomotion in knock-out and control mice. $A$, The mean $( \pm S D)$ values of speed and step amplitude during $B W$ locomotion in control mice $(N=8, n=120$ and $N=3, n=127$, respectively), $V_{0} 0_{\text {Glut }} K O$ mice $(N=3, n=67$ and $N=3, n=74$, respectively), and V0-KO mice $(N=4, n=48$ and $N=4, n=49$, respectively). $B$, The mean ( \pm SD) values of swing and stance duration as well as the frequency of locomotor movements during BW locomotion in control mice $(N=7, n=78), \mathrm{V}_{\text {Glut }} \mathrm{KO}$ mice $(N=3, n=62)$, and V0-KO mice $(N=4$, $n=43$ ). Statistically significant differences: in $\boldsymbol{A}$, difference between values of the mean step amplitude in control and V0-KO mice (unpaired $t$ test, $t_{(9)}=3.93, p=0.003$ ), as well as in V $0_{\text {Glut }}{ }^{-}$ $\mathrm{K} 0$ and V0-K0 mice (unpaired $t$ test, $t_{(3)}=3.55, p=0.04$ ); in $\boldsymbol{B}$, difference between values of the mean swing duration in control and V0-K0 mice (unpaired $t$ test, $t_{(5)}=3.20, p=0.02$ ), of the mean stance duration in control and V0-KO mice (unpaired $t$ test, $t_{(8)}=5.36, p=0.68 \times 10^{-5}$ ), of the mean frequency of locomotor movements in control and V0-KO mice (unpaired $t$ test, $t_{(4)}=-4.91, p=0.008$ ), as well as in $\mathrm{V}_{\text {Glut }} \mathrm{KO}$ and V0-K0 mice (unpaired $t$ test, $t_{(5)}=-4.08, p=0.009$ ). $C-E$, Swing duration and stance duration plotted versus cycle duration observed in control $(\boldsymbol{C}) \mathrm{V}_{\mathrm{Glut}^{-}} \mathrm{KO}(\boldsymbol{D})$, and V0-KO $(\boldsymbol{E})$ mice during BW locomotion. Note the strong positive correlation between cycle duration and stance duration, as well as weak or absence of correlation between cycle duration and swing duration observed in both control and $K 0$ mice. In $\boldsymbol{C}: N=12, n=233$; in $\boldsymbol{D}: N=3, n=121 ;$ in $\boldsymbol{E}: N=7, n=130$. $\boldsymbol{F}-\boldsymbol{H}$, Activity of left Tib (Tib-L) and right Tib (Tib-R), as well as a structure of corresponding locomotor cycles of the left hindlimb (HL-L) and right hindlimb (HL-R) during BW locomotion recorded in control (F), $\mathrm{VO}_{\text {Glut }} \mathrm{KO}(\boldsymbol{G})$, and V0-KO $(\boldsymbol{H})$ mice. The colored part of the cycle indicates the swing phase. Dashed lines demarcate cycles of the left hindlimb (reference limb). $\boldsymbol{I}, \boldsymbol{J}$, Circular diagrams showing the mean $( \pm S D)$ values of the phase shift between two hindlimbs $(I)$ and between two forelimbs $(I)$ during BW locomotion performed by control, V0 $0_{\text {Glut }}-\mathrm{KO}$, and V0-K0 mice. The number of control, $\mathrm{V}_{\mathrm{Glut}} \mathrm{KO}$, and $\mathrm{VO}-\mathrm{KO}$ mice and the corresponding number of analyzed reference limb cycles, respectively: in $I: N=11,3,7 ; n=126,68,79 ;$ in $J: N=11,4,7 ; n=103,57,56$. 
A Control

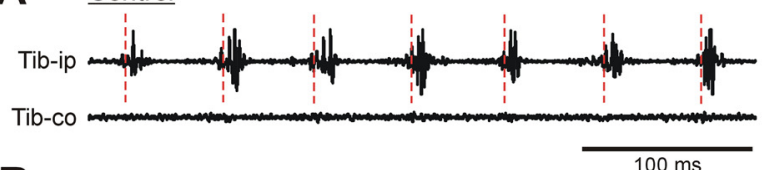

B $\quad \underline{V O}_{G / u t}-K O$

$100 \mathrm{~ms}$
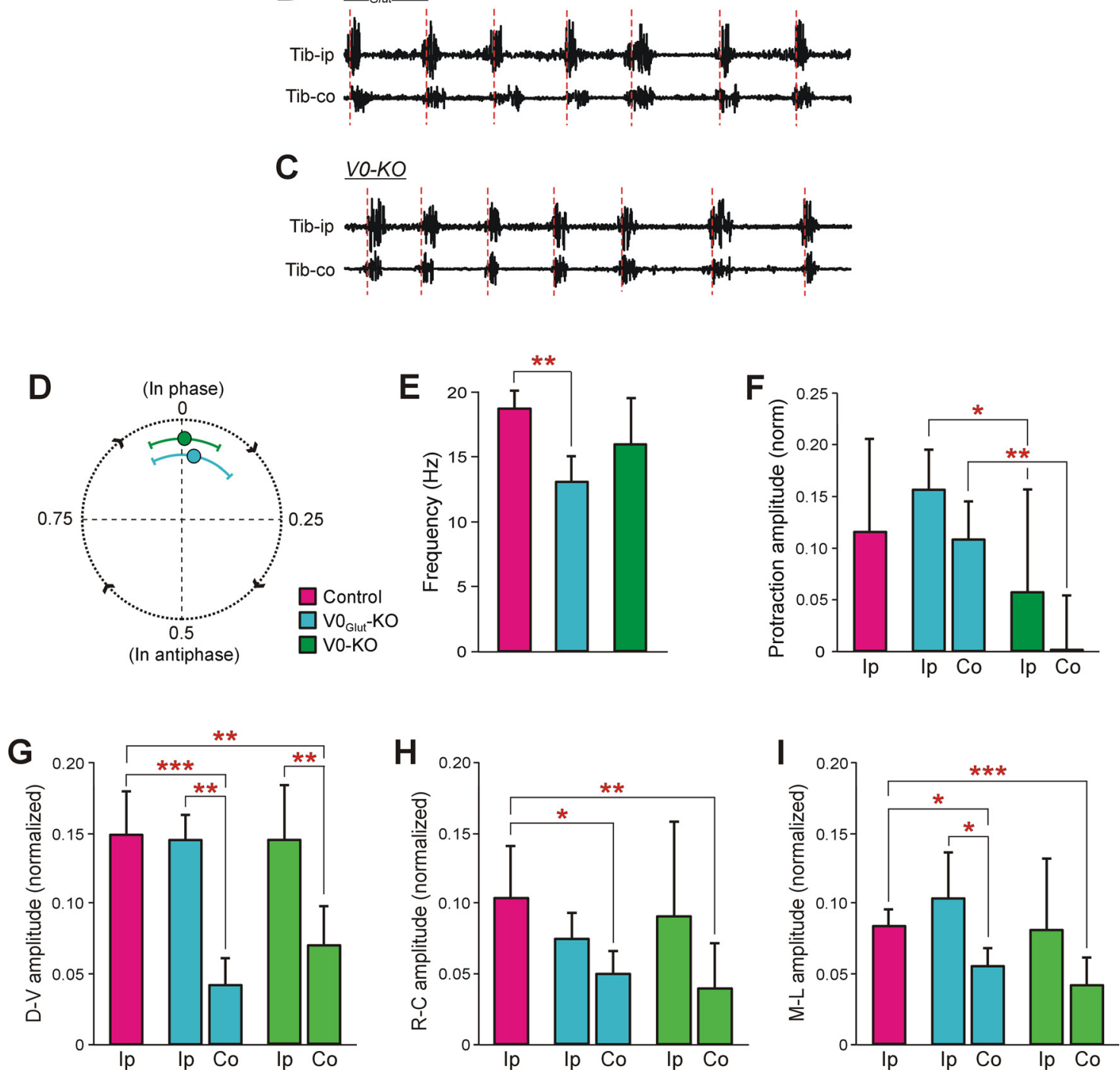

Figure 3. Characteristics of scratching movements performed by control and knock-out mice. $A-C$, Representative examples of activity of the left and right Tib during scratching evoked by unilateral stimulation of the pinna in control $(\boldsymbol{A}), \mathrm{V}_{\mathrm{Glut}} \mathrm{KO}(\boldsymbol{B})$, and $\mathrm{VO}-\mathrm{KO}(\boldsymbol{C})$ mice. Tib-ip, Tib ipsilateral to the stimulation site; Tib-co, Tib contralateral to the stimulation site. Note, that in control mice rhythmic activity was observed in Tib-ip only, while in both $\mathrm{V}_{\text {Glut }} \mathrm{KO}$ and V0-KO mice synchronous rhythmic bursts of activity in Tib-ip and Tib-co were generated. Red dashed lines demarcate the scratching cycles. $\boldsymbol{D}$, Circular diagram showing the mean $( \pm S D)$ value of the phase shift between movements of hindlimbs during scratching performed by $\mathbf{V}_{\mathrm{Glut}}-K 0$ $(N=4, n=46)$ and V0-KO $(N=6, n=76)$ mice. $\boldsymbol{E}$, The mean frequency ( \pm SD) of scratching in control $(N=6, n=63), V_{\text {Glut }}-K 0(N=4, n=63)$, and V0-KO (N=7, $\left.n=89\right)$ mice. $\boldsymbol{F}-\boldsymbol{I}$, The mean $( \pm S D)$ values of the normalized to the body length amplitude of the limb protraction $(\boldsymbol{F})$, and of the amplitude of the scratching movements in the dorsoventral $(\boldsymbol{G})$, rostrocaudal $(\boldsymbol{H})$, and mediolateral $(I)$ directions in control and $\mathrm{KO}$ mice. Ip, hindlimb ipsilateral to stimulation site; $C_{0}$, hindlimb contralateral to stimulation site. In $F$ : control, $N=7, n=11$; ipsilateral limb of $\mathrm{V}_{\text {Glut }} \mathrm{KO}$ mice, $N=4, n=15$; contralateral limb of V0 Glut $-\mathrm{KO}$ mice, $N=7, n=15$; ipsilateral limb of V0-KO mice, $N=8, n=16$; contralateral limb of V0-K0 mice, $N=8, n=16$. In G: control, $N=5, n=84$; ipsilateral limb of V $0_{\text {Glut }}-K O$ mice, $N=4, n=84$; contralateral limb of V0 Glut $K 0$ mice, $N=3, n=50$; ipsilateral limb of V0-KO mice, $N=6, n=273$; contralateral limb of V0-KO mice, $N=6, n=226$. In $\boldsymbol{H}$ : control, $N=6, n=108$; ipsilateral limb of V $0_{\text {Glut }} \mathrm{KO}$ mice, $N=4, n=98$; contralateral limb of $\mathrm{V}_{\text {Glut }} \mathrm{KO}$ mice, $N=4, n=98$; ipsilateral limb of V0-K0 mice, $N=6$, $n=181$; contralateral limb of V0-K0 mice, $N=6, n=181$. In I: control, $N=6, n=181$; ipsilateral limb of V0 $0_{\text {Glut }}-\mathrm{KO}$ mice, $N=4, n=179$; contralateral limb of V0 $0_{\text {Glut }} \mathrm{K} 0 \mathrm{mice}, N=4, n=162$; ipsilateral limb of V0-KO mice, $N=7, n=288$; contralateral limb of V0-K0 mice, $N=7, n=286$. Indication of significance level: ${ }^{*} p<0.05 ;{ }^{* *} p<0.01$; ${ }^{* * *} p<0.001$.

similar to that in control mice, while in $\mathrm{V}_{\mathrm{Glut}}-\mathrm{KO}$ mice it was slightly lower $(13.07 \pm 1.96$ vs $18.79 \pm 1.44 \mathrm{~Hz}$, respectively; unpaired $t$ test, $t_{(5)}=5.01, p=0.004$; Fig. $3 E$ ). During the bilateral scratching, knock-out mice used the base of the tail to support the hindquarters.

Scratching movements performed by hindlimb ipsilateral and contralateral to the side of stimulation differed. In both V0-KO and $\mathrm{V} 0_{\mathrm{Glut}} \mathrm{KO}$ mice, the average amplitudes of the ipsilateral limb movements in rostrocaudal, dorsoventral, and mediolateral directions did not differ significantly from those observed in control animals (Fig. 3G-I). In contrast, in each of three directions, the average amplitudes of movements of the contralateral limb were significantly smaller than those in control mice (in $\mathrm{V}_{\mathrm{Glut}^{-}}$ KO mice: dorsoventral direction, unpaired $t$ test, $t_{(6)}=5.99$, 
$p=9.6 \times 10^{-4}$; rostrocaudal direction, $t_{(6)}=3.17, p=0.02$; mediolateral direction, $t_{(6)}=3.57, p=0.01$; in $\mathrm{V0}-\mathrm{KO}$ mice: dorsoventral direction, $t_{(8)}=4.36, p=0.002$; rostrocaudal direction, $t_{(10)}=3.28, p=0.008$; mediolateral direction, $t_{(10)}=4.79$, $p=0.0007$; Fig. $3 G-I$ ). The amplitudes of movements were also smaller than those observed in the ipsilateral limb (Fig. 3G-I). The differences were significant for movements in dorsoventral direction (unpaired $t$ test, $t_{(4)}=7.16, p=0.002$ ) and mediolateral direction (unpaired $t$ test, $t_{(4)}=2.78, p=4.9 \times 10^{-2}$ ) in $\mathrm{V}_{\text {Glut }^{-}}$ $\mathrm{KO}$ mice, as well as in dorsoventral direction (unpaired $t$ test, $\left.t_{(9)}=3.84, p=0.004\right)$ in V0-KO mice.

These results suggest that during scratching in control mice, the $\mathrm{V} 0_{\text {Glut }}$ subpopulation actively inhibits the network generating scratching movements on the contralateral limb. In $\mathrm{KO}$ mice exhibiting bilateral scratching, it is most likely that the scratching network ipsilateral to the stimulation side activates and synchronizes the operation of the contralateral one.

To evaluate the postural component of the scratching, we measured the amplitude of the limb protraction toward the stimulation point, which preceded the rhythmical movements ( $\mathrm{P}$ in Fig. 1C). In $\mathrm{V}_{\mathrm{Glut}^{-}} \mathrm{KO}$ mice, the average amplitudes of the ipsilateral and contralateral limb protraction were similar, and they also were similar to that observed in control mice, while the corresponding amplitudes of protraction in $\mathrm{V} 0-\mathrm{KO}$ mice were significantly smaller than those in $\mathrm{V}_{\text {Glut }}-\mathrm{KO}$ mice (unpaired $t$ test, $t_{(8)}=2.33, p=0.04$ and $t_{(8)}=3.94, p=0.004$, respectively; Fig. $3 F)$. As in control mice, in all $\mathrm{KO}$ mice the body was bent to the stimulation side during scratching. However, in $\mathrm{V} 0-\mathrm{KO}$ mice, because of the small amplitude of the protraction, the ipsilateral limb usually did not reach the stimulated site, making scratching reflex completely inefficient. These results suggest that, at least one or both of the commissural $\mathrm{VO}_{\mathrm{D}}$ and the ipsilaterally projecting $\mathrm{V} 0_{\mathrm{C}}$ subpopulations contribute to generation of the postural component of scratching.

Thus, the $\mathrm{V} 0_{\mathrm{Glut}}$ subpopulation and the $\mathrm{V} 0_{\mathrm{D}}-\mathrm{V} 0_{\mathrm{C}}$ subpopulations appear to be differentially involved in the control of different aspects of scratching.

\section{V0 neurons are essential for execution of righting behavior}

To evoke the righting behavior, we released animals in an upside-down position. Control mice $(N=11)$ performed righting in two stages. Stage 1 consisted of ventral flexion of the trunk accompanied by twisting and lateral bending (oblique bending) of the forequarters in relation to the hindquarters. This maneuver caused the displacement of the center of mass to the side of the twisting and produced a sufficient torque to rotate the body toward the side of twisting. The body rotation was accompanied by movements of forelimbs toward the surface. As a result, the forequarters assumed a position with forelimbs standing on the surface, while the hindquarters turned from upside-down position to the side (Fig. 1E, moment 2). During stage 2, the hindquarters rotated in relation to the forequarters until they reached a position close to the dorsal side up with hindlimbs standing on the surface (Fig. 1E, moment 3). At the beginning of stage 2, the rotation of the hindquarters was accompanied by flexion of the hindlimbs and often performed when the hindquarters were in the air, suggesting that rotation was caused purely by the contraction of trunk muscles. After accomplishing stage 2, the animal assumed the basic body configuration characteristic for standing (Fig. 1E, moment 4).

Both $\mathrm{V0}-\mathrm{KO}$ and $\mathrm{V}_{\mathrm{Glut}}-\mathrm{KO}$ mice were able to perform the righting behavior. However, $\mathrm{V} 0-\mathrm{KO}$ mice (animals, $N=10$; trials, $n=75$ ) needed in most cases ( $72 \%$ of trials) from two to nine attempts to succeed (Fig. 4A). In unsuccessful attempts, V0-KO mice were not able to accomplish stage 1 . In particular, they could not succeed to assume the body configuration required for producing the torque rotating the body. Instead, they performed sequential attempts to twist the body to the right, to twist the body to the left, or to perform ventral bending without twisting. However, in all cases when V0-KO mice succeeded to perform stage 1, stage 2 was performed in the first attempt. By contrast, all control mice $(N=11, n=94)$ and all $\mathrm{V} 0_{\mathrm{Glut}}-\mathrm{KO}$ mice $(N=5$, $n=45$ ) performed successful righting during the first attempt in all trials (Fig. 4A). The latency of righting (i.e., a time from the moment of release of the animal in the upside-down position to the beginning of stage 1 ) in $\mathrm{V}_{\mathrm{Glut}^{-}} \mathrm{KO}$ mice was twofold longer than in control mice, and in $\mathrm{V} 0-\mathrm{KO}$ mice (in trials with the first successful attempt) it was twofold longer than in $\mathrm{V0}_{\mathrm{Glut}}-\mathrm{KO}$ mice (unpaired $t$ test, $t_{(7)}=3.74, p=0.007$, and $t_{(11)}=-3.00$, $p=0.01$, respectively; Fig. $4 B$ ). The increase in latency to initiate righting from control to $\mathrm{V}_{\mathrm{Glut}}-\mathrm{KO}$ mice and then to $\mathrm{V0}-\mathrm{KO}$ mice suggests that all V0 subpopulations contribute to the initiation of righting. In control mice, the durations of stage 1 and stage 2 were similar while in both $\mathrm{V} 0-\mathrm{KO}$ and $\mathrm{V} 0_{\text {Glut }}-\mathrm{KO}$ mice the duration of stage 2 was more than twofold longer than the duration of stage 1 (unpaired $t$ test, $t_{(10)}=-4.57, p=0.001$, and $t_{(8)}=-8.05, p=4.2 \times 10^{-5}$, respectively; Fig. $\left.4 C\right)$. The duration of stage 1 in $\mathrm{V}_{\mathrm{Glut}^{-}} \mathrm{KO}$ mice was similar to that observed in control mice, while in $\mathrm{V} 0-\mathrm{KO}$ mice, it was more than fivefold longer than in control mice (unpaired $t$ test, $t_{(6)}=-6.95, p=0.0004$ ). These results suggest that $\mathrm{V} 0_{\text {Glut }}$ neurons contribute to the generation of stage 2 only, while at least one or both of the $\mathrm{V} 0_{\mathrm{D}}$ and $\mathrm{V} 0_{\mathrm{C}}$ subpopulations contribute to the generation of both stage 1 and stage 2 .

Thus, the $\mathrm{V}_{\text {Glut }}$ subpopulation and the $\mathrm{V}_{\mathrm{D}^{-}}-\mathrm{V} 0_{\mathrm{C}}$ subpopulations appear to be differentially involved in the control of different aspects of the righting behavior.

\section{Ablation of $\mathrm{V} 0$ neurons decreases the efficacy of postural corrections}

Postural corrections were evoked by lateral tilts of the supporting platform (for details, see Materials and Methods). We found that, as in all tested terrestrial quadrupeds (Deliagina et al., 2000, 2006; Beloozerova et al., 2003), in wild-type mice $(N=8)$ as well as in $\mathrm{V} 0-\mathrm{KO}(N=9)$ and $\mathrm{V}_{\mathrm{Glut}}-\mathrm{KO}$ mice $(N=7)$ lateral tilt of the supporting platform (Fig. $1 F, G$, angle $\alpha$ ) caused the extension of limbs on the side of the tilt and simultaneous flexion of the contralateral limbs (Fig. $1 F$ ), leading to the displacement of the dorsoventral axis of the trunk toward the vertical (Fig. 1F,G, angle $\gamma$ ). The hindlimb corrective movements were caused by an increase in the activity of extensors in the limb moving down and by a decrease in activity of extensors in the opposite hindlimb (Fig. 1H). As in other terrestrial quadrupeds (Deliagina et al., 2000, 2006; Beloozerova et al., 2003), the postural corrections in mice did not fully compensate the distortion of the trunk orientation caused by the platform tilt, and after their execution the dorsoventral axis of the trunk was still deviated from the vertical (Fig. $1 F, G$, angle $\beta$ ).

Both $\mathrm{V}_{\mathrm{Glut}}-\mathrm{KO}$ and $\mathrm{V} 0-\mathrm{KO}$ mice exhibited postural corrections in response to the platform tilts with EMG pattern similar to that in control (Figs. $4 F, 1 H$, compare EMG pattern in $\mathrm{V} 0$ $\mathrm{KO}$, control mice, respectively). To reveal the efficacy of postural corrections stabilizing the dorsal side-up orientation of the caudal part of the trunk, we calculated the coefficient of its stabilization (see Materials and Methods). A coefficient of stabilization equal to 1 would indicate that postural corrections are perfect. 

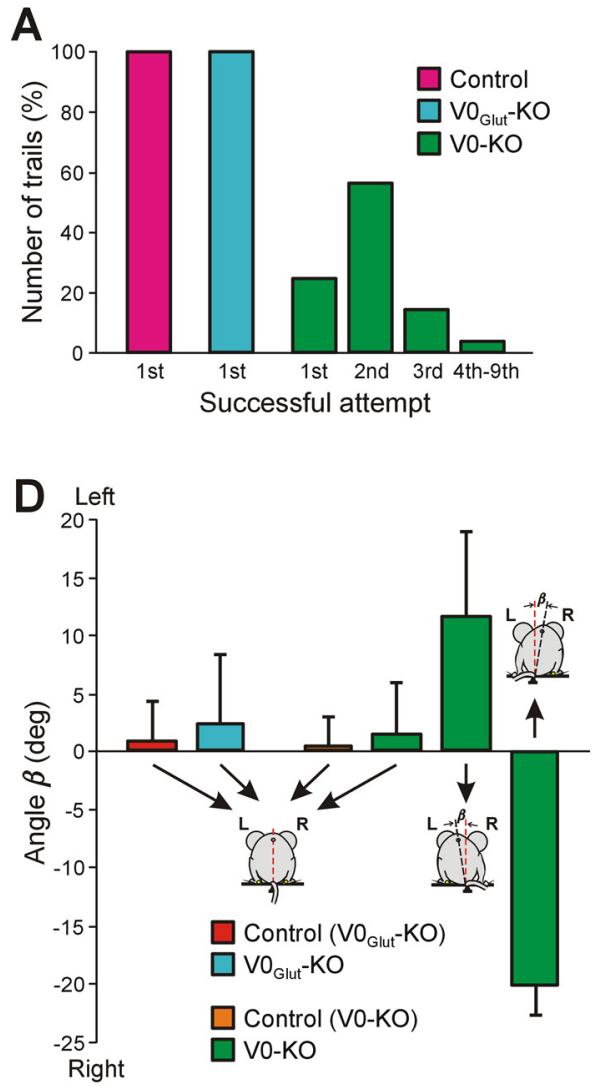
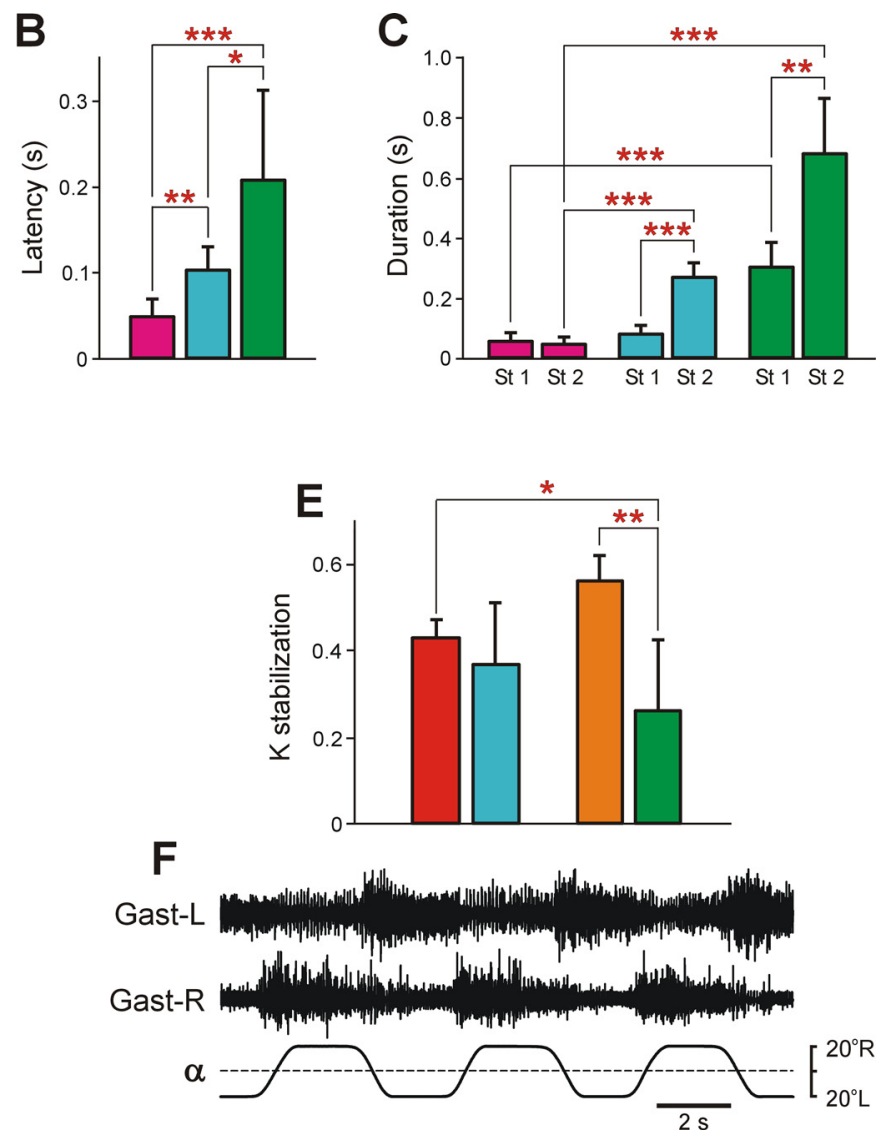

Figure 4. Comparison of postural functions in control and knock-out mice. $A$, Relative number of trials in which control $(N=11, n=94), \mathrm{V} 0_{G l u t}-K 0(N=5, n=45)$, and V0-KO $(N=10, n=75)$ mice performed successful righting in the first (1st), second (2nd), third (3rd), and fourth to ninth (4th-9th) attempt. $B$, Comparison of latencies of righting performed successfully from the first attempt in control $(N=6, n=26), \mathrm{V}_{\text {Glut }}-\mathrm{KO}(N=5, n=29)$, and V0-KO $(N=10, n=19)$ mice in trials in which the first attempt to perform righting was successful. C, Comparison of duration of 1st (St 1) and stage 2 (St 2) of the righting in control $(N=7, n=47), V_{G l u t}-K 0(N=5, n=45)$, and V0-KO (N=6, $\left.n=64\right)$ mice. $\boldsymbol{D}$, The mean ( $\pm \mathrm{SD}$ ) value of the tilt of the caudal part of the trunk in relation to vertical (angle $\beta)$ in $\mathrm{V}_{\mathrm{Glut}}-\mathrm{KO}$ wild-type littermates [control $\left.\left(\mathrm{V} 0_{G l u t}-\mathrm{K} 0\right), N=5, n=26\right)$ ], V0 Glut $-K 0$ mice $(N=9, n=24)$, V0-KO wild-type littermates [control (VO-KO), $N=3, n=20)$ ], and V0-K0 mice $(N=6)$ standing on the horizontal platform. Note that V0-K0 mice had different postures: two animals $(n=9)$ maintained vertical orientation of the caudal part of the trunk; in three animals $(n=13)$ it was tilted to the left; and in one animal $(n=3)$ it was tilted to the right. $\boldsymbol{E}$, The mean $( \pm S D)$ value of the coefficient of stabilization (K stabilization) exhibited by $\mathbf{V}_{\mathrm{Glut}}-\mathrm{K} 0$ wild-type littermates $(N=5, n=104)$, V0 $0_{\text {Glut }}$-KO mice $(N=9, n=157)$, V0-KO wild-type littermates $(N=3, n=36)$, and V0-KO mice $(N=7, n=161)$ during postural corrections caused by the lateral tilts of the supporting platform. $F$, Activity of the left Gast (Gast-L) and right Gast (Gast-R) recorded in V0-KO mice during postural corrections caused by the platform tilts. Statistically significant differences: in $\boldsymbol{B}$, difference between values of the mean latency in control and $\mathrm{V}_{0_{\text {Glut }}}-\mathrm{KO}$ mice (unpaired $t$ test, $t_{(7)}=3.74, p=0.007$ ), in control and in $\mathrm{V} 0$-KO mice (unpaired $t$ test, $\left.t_{(10)}=-4.69, p=0.0008\right)$, in $\mathrm{V}_{\mathrm{Glut}}-\mathrm{KO}$ and V0-KO mice (unpaired $t$ test, $\left.t_{(11)}=-3.00, p=0.01\right)$; in $C$, difference between values of the mean duration of $S t 1$ and $\mathrm{St} 2$ in $\mathrm{V}_{\text {Glut }}$-KO mice (unpaired $t$ test, $t_{(8)}=-8.05, p=4.2 \times 10^{-5}$ ) as well as in V0-KO mice (unpaired $t$ test, $t_{(10)}=-4.57, p=0.001$ ), between the duration of St 1 in control and V0-KO mice (unpaired $t$ test, $t_{(6)}=-6.95, p=0.0004$ ), between the duration of St 2 in control and V $0_{\text {Glut }}$-KO mice (unpaired $t$ test, $t_{(6)}=-10.27, p=5.0 \times 10^{-5}$ ), as well as in control and V0-KO mice (unpaired $t$ test, $t_{(5)}=8.29, p=0.0004$ ); in $\boldsymbol{E}$, difference between values of $\mathrm{K}$ stabilization in V0-K0 control and V0-K0 mice (unpaired $t$ test, $t_{(8)}=4.36, p=0.002$ ), and between $\mathrm{K}$ stabilization in $\mathrm{V}_{\text {Glut }}-\mathrm{K} 0$ control and $\mathrm{V} 0$-KO mice (unpaired $t$ test, $t_{(3)}=-3.66, p=0.035$ ).

We found that the mean value of the coefficient of stabilization in $\mathrm{V}_{\mathrm{Glut}}-\mathrm{KO}$ mice was similar to that in their wild-type littermates, while in $\mathrm{V0}-\mathrm{KO}$ mice, it was significantly lower than in their wild-type littermates (unpaired $t$ test, $t_{(8)}=4.36, p=0.002$; Fig. $4 E$ ). These results suggest that there is little contribution from the $\mathrm{V} 0_{\text {Glut }}$ subpopulation to the generation of postural corrections, while at least one or both of the $\mathrm{V} 0_{\mathrm{D}}$ and $\mathrm{V} 0_{\mathrm{C}}$ subpopulations are involved.

The majority of V0-KO mice had postural asymmetry when standing on a horizontal surface in contrast to $\mathrm{V} 0_{\mathrm{Glut}}-\mathrm{KO}$ mice and control mice, which had symmetrical body posture. In 12 of $15 \mathrm{~V} 0-\mathrm{KO}$ mice, the dorsoventral axis of the hindquarters was tilted to the left, while it was titled to the right in one animal. In addition, asymmetrical animals had the tail bent to the opposite side of the hindquarters tilt.

For the majority of animals, which were used to study postural corrections, we also characterized the orientation of the caudal part of the trunk when an animal was standing on the horizontal surface. For this purpose, the angle between the dorsoventral axis of the trunk and the vertical (Fig. $4 D$, angle $\beta$ ) was calculated. In control mice as well as in $\mathrm{V0}_{\mathrm{Glut}}-\mathrm{KO}$ mice, the mean value of angle $\beta$ was close to zero, suggesting that they maintained dorsal side-up orientation of the caudal part of the trunk. By contrast, of six V0-KO mice, in three animals the dorsoventral axis of the trunk was strongly tilted to the left $(\beta=$ $\left.11.6^{\circ} \pm 7.3^{\circ}, n=13\right)$, in one animal it was strongly tilted to the right $\left(\beta=-20.3^{\circ} \pm 2.5^{\circ}, n=3\right)$, and in two animals it was close to the vertical $\left(\beta=1.6^{\circ} \pm 4.4^{\circ}, n=9\right)$. The mean $( \pm \mathrm{SD})$ values of the coefficient of stabilization on the tilting platform in $\mathrm{V0}-\mathrm{KO}$ mice with close to dorsal side-up trunk orientation and with a strongly tilted trunk were similar $(0.30 \pm 0.06, N=2, n=66$, and $0.28 \pm 0.20, N=4, n=79$, respectively; unpaired $t$ test, $t_{(4)}=$ $-1.80, p=0.9)$. Together, these results show a specific involvement of the V0 subpopulations in the control of posture. 
Control
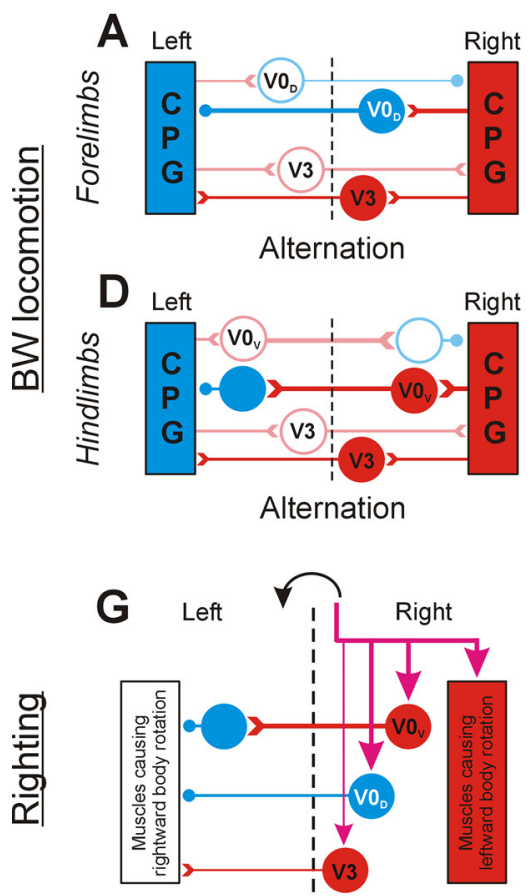

Quick Stage 2
$\underline{V 0}_{G l u t}-K O$

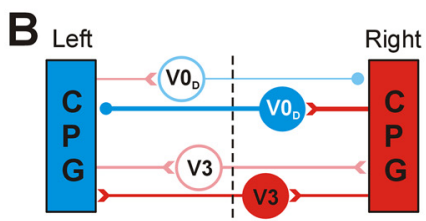

Alternation

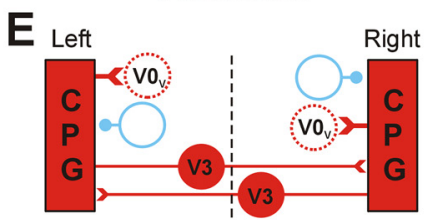

Hopping

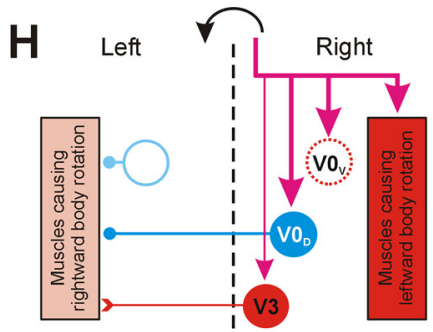

Slower Stage 2 $\underline{\text { VO-KO }}$

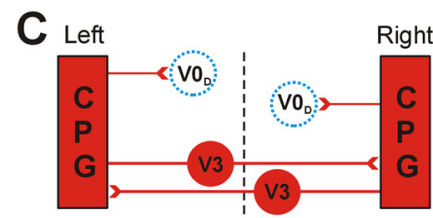

Hopping

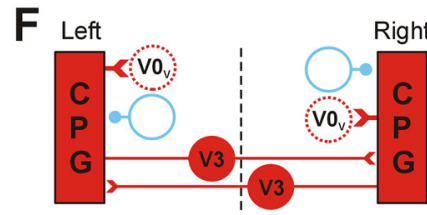

Hopping

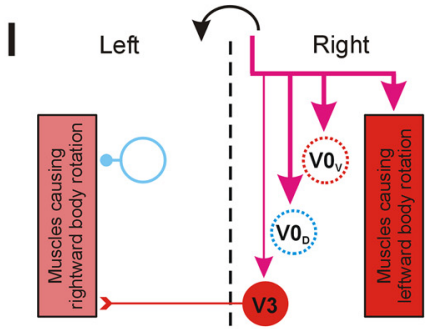

Slowest Stage 2
Control

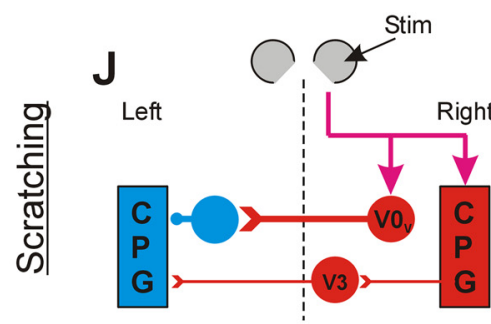

Unilateral scratching

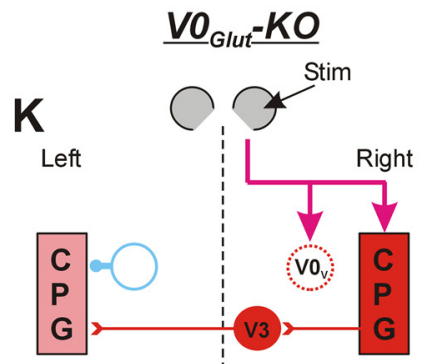

Bilateral scratching
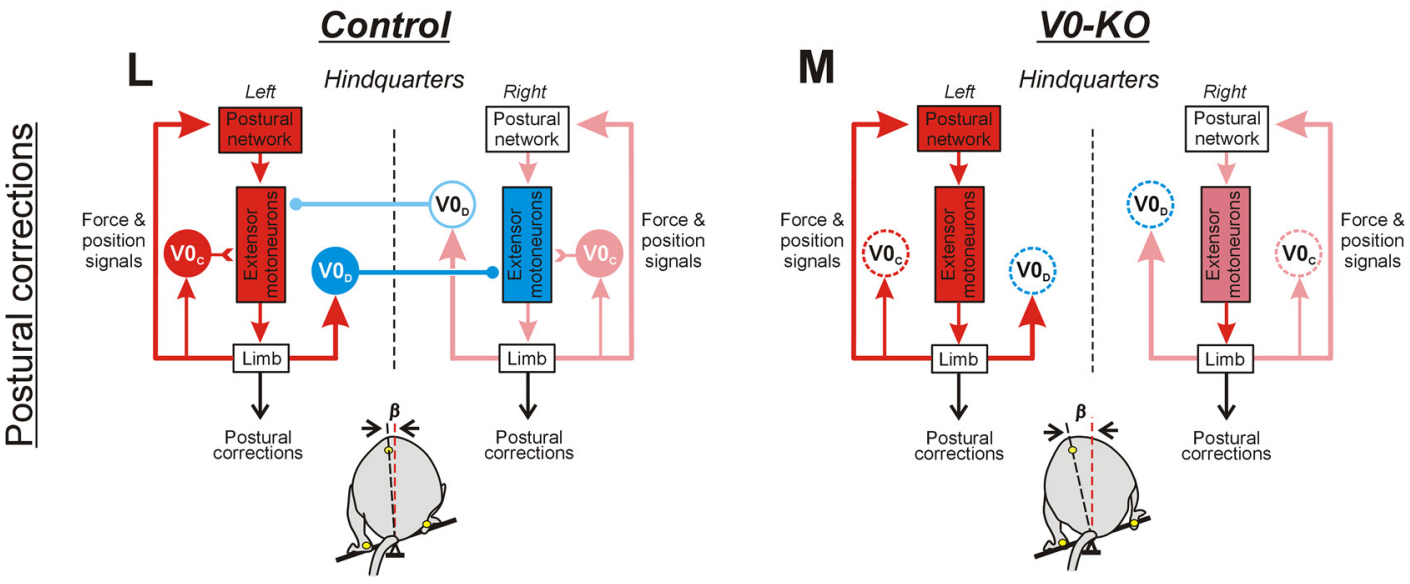

Figure 5. Diagrams depicting the changes in network configurations as inferred from the ablation of $\mathrm{V}_{\mathrm{v}}$ and all V0 CINs. Designations are as follows: activated inhibitory and excitatory neurons are shown in blue and red, respectively; inactive inhibitory and excitatory neurons are indicated by light blue and pink empty circles, respectively; ablated neurons are indicated by dotted circles; progressive increase in excitation level is indicated by a gradual increase in the intensity of red color. Open triangles, excitatory synapses; small filled circles, inhibitory synapses. The thickness of lines indicates the strength of the produced effect. Only CINs contributing to the generation of a behavior (as inferred from the perturbed behavior in KO mice) are shown. In $\boldsymbol{A}-\boldsymbol{F}, \boldsymbol{J}$, and $\boldsymbol{K}$, for simplicity, only parts of left and right CPGs generating the same phase of the cycle are shown. Purple arrows indicate descending commands causing the behavior. $A-F$, Proposed networks underlying the coordination of forelimbs $(\boldsymbol{A}-\boldsymbol{C})$ and hindlimbs $(\boldsymbol{D}-\boldsymbol{F})$ during $\mathrm{BW}$ locomotion, in control mice (Control; $\boldsymbol{A}, \boldsymbol{D}), \mathrm{V} 0_{\mathrm{Glut}}-\mathrm{KO}$ mice $\left(\mathrm{V} \mathbf{G}_{\mathrm{Glut}} \mathrm{KO} ; \boldsymbol{B}, \boldsymbol{E}\right)$, and V0- 


\section{Discussion}

The present study examines four basic motor behaviors-BW locomotion, scratching, righting, and postural corrections-after genetic manipulation of molecularly defined and projection-specific interneurons. We demonstrate that different subpopulations of V0 neurons play diversified roles in control of these four behaviors.

Below we considered modifications in the spinal networks that could lead to distortions in the left-right coordination observed in $\mathrm{KO}$ mice. However, in $\mathrm{V}_{\mathrm{Glut}}-\mathrm{KO}$ mice, $\mathrm{V} 0_{\mathrm{V}} \mathrm{CINs}$ are ablated not only in the spinal cord but also in the brain. In addition, other glutamatergic neurons in the brain derived from Dbx1-expressing progenitors could be also affected (Gray, 2013; Ruangkittisakul et al., 2014). This may lead to a change in supraspinal influences contributing to observed distortions of behavior. Such a possibility cannot be ruled out in the case of righting behavior and postural corrections. However, the fact that leftright coordination during backward locomotion and during scratching in spinal animals is similar to that observed in intact animals (Sherrington, 1906; Courtine et al., 2009), and, considering that the spinal $\mathrm{V0}_{\mathrm{G}}$ subpopulation is very small $(\sim 2 \%)$, we

KO mice (VO-KO; $C, F$ ). In control mice $(A, D)$, there is a predominance in activation of $\mathrm{VO}_{D}$ CINs $(\boldsymbol{A})$ and $\mathrm{V}_{\mathrm{V}} \mathrm{CINs}(\boldsymbol{D})$ in the cervical and lumbosacral enlargement, respectively, leading to alternation in swing/stance phases performed by forelimbs $(\boldsymbol{A})$ as well as by hindlimbs (D). Ablation of $\mathrm{VO}_{\mathrm{V}}$ CINs $(\boldsymbol{E})$ leads to synchronization of phases generated by the left and right CPGs in the lumbosacral enlargement (possible mediated by excitatory V3 interneurons), resulting in hindlimb synchrony. By contrast, it does not affect the alternation of forelimbs $(\boldsymbol{B})$. Ablation of both $\mathrm{VO}_{\mathrm{V}}$ and $\mathrm{VO}_{\mathrm{D}}$ CINs in V0-KO mice $(\boldsymbol{C}, \boldsymbol{F})$ leads to synchronization of the left and right CPGs in lumbosacral and cervical enlargement resulting in synchronous leg movement of both forelimbs $(\boldsymbol{C})$ and hindlimbs $(\boldsymbol{F})$. $\mathbf{G}-\boldsymbol{I}$, Proposed network configuration underlying generation of stage 2 of righting in control $(G), V_{G l u t}-K O(H)$, and V0-KO $(I)$ mice. In control mice $(\boldsymbol{G})$, sensory information signaling that hindquarters are laying on the right side causes the activation of trunk muscles that rotates the hindquarter to the left, as well as the activation of $\mathrm{VO}_{\mathrm{V}}, \mathrm{V}_{\mathrm{D}}$, and excitatory (V3) CINs. Because of predominance in the inhibitory effect produced by $\mathrm{V}_{\mathrm{V}}$ and $\mathrm{V}_{\mathrm{D}}$ CINs over excitatory CINs (presumably, V3 CINs) acting on motor neurons of muscles causing leftward rotation of the hindquarters, quick leftward rotation of the hindquarters is performed. Ablation of $\mathrm{V}_{V}$ CINs in $\mathrm{V}_{\text {Glut }}-\mathrm{KO}$ mice $(\boldsymbol{H})$ and all VO CINs in V0-KO mice (I) leads to a progressive decrease in the asymmetry of muscles rotating hindquarters in opposite directions (because of progressive disinhibition of motoneurons of muscles causing rightward rotation), which results in an increase in duration of rightward rotation in $\mathrm{VO}_{\text {Glut }} \mathrm{KO}$ mice compared with control mice, and in V0-KO mice compared with $\mathrm{V}_{\text {Glut }}-\mathrm{KO}$ mice. $\boldsymbol{J}, \boldsymbol{K}$, Proposed network configuration underlying the coordination of hindlimbs during scratching in control $(\boldsymbol{(})$ and $\mathrm{V}_{\text {Glut }} \mathrm{KO}(\boldsymbol{K})$ mice. In control mice $(\boldsymbol{J})$, sensory signals from the right pinna activate the ipsilateral scratching $\mathrm{CPG}$ as well as $\mathrm{VO}_{\mathrm{V}} \mathrm{CINs}$ producing a strong inhibitory effect on the contralateral $\mathrm{CPG}$. As a result, scratching is performed by the right hindlimb only. Ablation of $\mathrm{V}_{\mathrm{V}} \mathrm{CINs}$ in $\mathrm{V}_{\text {Glut }}-\mathrm{KO}$ mice $(K)$ results in the activation of left scratching CPG and synchronization of its activity with the right CPG mediated by excitatory CINs. As a result, synchronous scratching movements are performed by both hindlimbs. $L, M$, Proposed network configuration underlying the generation of postural corrections needed to stabilize the caudal part of the trunk in the frontal plane in control and KO mice. In control mice ( $\boldsymbol{L}$ ), the tilt of the platform to the left (bottom) causes sensory signals about left limb loading, which lead to the activation of ipsilateral extensor motor neurons possibly partly mediated by $\mathrm{VO}_{\mathrm{c}}$ neurons, resulting in extension of the left limb. Simultaneously, the same sensory signals activate ipsilateral $\mathrm{V}_{D}$ CINs, which inhibit contralateral extensor motor neurons. This leads to flexion of the right limb. Large-amplitude extension and flexion movements of the left and right limbs, respectively, move the dorsoventral axis of the trunk to a vertical position, effectively restoring the disturbed trunk orientation (small value of angle $\beta$, bottom). Ablation of $\mathrm{V}_{\mathrm{D}} \mathrm{CINs}$ and $\mathrm{V}_{\mathrm{C}}$ neurons in $\mathrm{V} 0-\mathrm{KO}$ mice $(M)$ leads to disinhibition of contralateral extensor motor neurons (resulting in a reduction in the right limb flexion) and some decrease in activity of ipsilateral extensor motor neurons (resulting in some reduction of the left limb extension). As a result, limb corrective movements produce smaller displacement of the dorsoventral axis of the trunk toward the vertical, and, thus, the efficacy of postural corrections decreases [value of angle $\beta$ (bottom) is larger than that in control mice $(L)]$. suggest that most likely the distortions in the left-right coordination during these behaviors observed in $\mathrm{V}_{\mathrm{Glut}}-\mathrm{KO}$ mice were caused mainly by the ablation of spinal $\mathrm{V}_{\mathrm{V}} \mathrm{CINs}$.

In $\mathrm{V} 0-\mathrm{KO}$ mice, all $\mathrm{V} 0$ interneurons are ablated in the spinal cord. However, since $\mathrm{V}_{\mathrm{C}}$ cells project ipsilaterally and form $\mathrm{C}$ boutons with motoneurons, they can modulate the activity of motor neurons (Zagoraiou et al., 2009). This modulation has been shown to affect the amplitude of swimming bouts but not the left-right coordination (Zagoraiou et al., 2009). We therefore propose that changes in the left-right coordination in $\mathrm{V0}-\mathrm{KO}$ mice compared with that in $\mathrm{V}_{\mathrm{Glut}}-\mathrm{KO}$ mice are caused by the ablation of $\mathrm{V}_{\mathrm{D}} \mathrm{CINs}$, while the ablation of the $\mathrm{V} 0_{\mathrm{C}}$ subpopulation can contribute to other observed deficits such as decreased scratching movement amplitude, change of the main characteristics of BW locomotor movements, possible weakness of movements that could lead to the distortion of righting, and postural corrections.

\section{Different subpopulations of V0 CINs determine alternation of forelimbs and hindlimbs during BW locomotion}

The analysis of our results leads us to suggest that the likely explanation of the obtained results is that different subpopulations of V0 CINs determine the alternation of forelimbs and hindlimbs during $\mathrm{BW}$ locomotion. $\mathrm{VO}_{\mathrm{V}} \mathrm{CINs}$ determine the alternation of the hindlimbs, while inhibitory $\mathrm{V}_{\mathrm{D}} \mathrm{CINs}$ seem to be mainly responsible for the alternation of the forelimbs. Thus, the role of $\mathrm{V} 0 \mathrm{~V}_{\mathrm{V}} \mathrm{CINs}$ in the control of hindlimb coordination during BW locomotion is similar to that reported earlier for FW locomotion performed with the same frequencies corresponding to trot (Talpalar et al., 2013; Bellardita and Kiehn, 2015). During both FW trot and BW locomotion, despite their excitatory nature, glutamatergic $\mathrm{V0}_{\mathrm{V}}$ CINs play an inhibitory functional role, presumably through inhibitory contralaterally located interneurons (Crone et al., 2008; Kiehn, 2016). It was also noted that forelimb alternation was present in $\mathrm{V0}_{\mathrm{Glut}} \mathrm{KO}$ mice during $\mathrm{FW}$ trot (Talpalar et al., 2013). Thus, we assume that $\mathrm{V} 0_{\mathrm{V}} \mathrm{CINs}$ are not necessary for forelimb alternation during both FW trot and BW locomotion.

In quadrupeds, at the same frequency of locomotor movements, the speed of BW locomotion is significantly lower than that of FW locomotion (Buford et al., 1990; Vilensky and Cook, 2000). The observation that the same subpopulation of V0 CINs determines the hindlimb coordination during both FW and BW locomotion performed at the same frequency but with different speed, suggests that the supraspinal command that sets a definite frequency of locomotor movements but not speed, recruits a specific subpopulation of CINs, which is responsible for left-right limb coordination at the set frequency. Most likely, this command is addressed to the part of the spinal locomotor network involved in the generation of both FW and BW locomotion. In cats, this network generates the vertical component of the step and contains the rhythmgenerating mechanism (Musienko et al., 2012; Zelenin et al., 2016; Deliagina et al., 2019).

Figure $5 A-F$ summarizes the suggested modifications in the BW locomotor networks caused by the ablation of $\mathrm{V} 0_{\mathrm{V}}$ CINs and by the ablation of all VO CINs.

\section{Specific subpopulations of V0 neurons control different aspects of scratching}

Scratching is a spinal rhythmic reflex, which has been studied in considerable detail (Sherrington, 1906, 1910; Deliagina et al., 1975, 1983; Deliagina, 1977; Berkinblit et al., 1978; Stein, 1983). 
Rhythmic scratching movements of the hindlimb are generated by a central pattern generator (CPG) network located ipsilaterally in the lumbosacral enlargement (Berkinblit et al., 1978; Deliagina et al., 1983). In all studied mammals, unilateral stimulation of the receptive field evokes scratching movements performed by the ipsilateral hindlimb (Sherrington, 1906, 1910; Deliagina et al., 1975; Deliagina, 1977), while bilateral stimulation causes alternation in scratching episodes performed by the left and right limb suggesting a strong reciprocal inhibition between the left and right scratching networks (Deliagina, 1977). Our results suggest that excitatory $\mathrm{V0}_{\mathrm{V}}$ CINs most likely mediate this inhibition since their ablation leads to bilateral scratching in response to unilateral stimulation.

It is not clear whether descending commands-formed on the basis of sensory signals from the receptive field-cause a direct activation of $\mathrm{V0}_{\mathrm{V}}$ CINs or their activation is mediated by spinal scratching networks (Fig. $5 J$ ). In $\mathrm{V}_{\mathrm{Glut}}-\mathrm{KO}$ mice, the amplitude of scratching movements in all planes in the hindlimb ipsilateral to the side of stimulation was significantly larger than that in the contralateral one. This suggests that the ipsilateral scratch CPG is activated first and then in turn activates and synchronizes the contralateral scratch CPG through excitatory (possibly V3) populations of CINs (Fig. $5 K$ ).

\section{Specific subpopulations of V0 neurons contribute to control of different aspects of righting behavior}

Righting behavior is initiated by sensory information of different modality signaling a distortion of the basic body orientation in space, and according to Magnus (1924) represents a sequence of righting reflexes. The basic networks underlying the righting behavior reside in the brainstem, cerebellum, and spinal cord (Musienko et al., 2008).

In both control and $\mathrm{KO}$ mice, righting of the upside-down position consisted of stage 1 (righting of forequarters) followed by stage 2 (righting of hindquarters). We found that all subpopulations of V0 neurons contribute to the processing of sensory information causing the initiation of stage 1 . Ablation of the $\mathrm{V} 0_{\mathrm{V}}$ subpopulation caused a delay in activation of the network generating stage 1 but distorted neither its selective activation nor its operation. Ablation of all V0 neurons led to unsuccessful attempts to perform stage 1, suggesting that aberrant networks were activated. Considering that the $\mathrm{V} 0_{\mathrm{C}}$ subpopulation represents only $2 \%$ of the $\mathrm{V} 0$ population, it seems reasonable to suggest that the $\mathrm{V}_{\mathrm{D}}$ CINs have the strongest influence on the phenotype and therefore are essential elements of the network generating stage 1 .

We found a dramatic increase in the duration of stage 2 in both $\mathrm{V} 0$ and $\mathrm{V} 0_{\mathrm{Glut}} \mathrm{KO}$ mice compared with control mice, with the longest duration in the $\mathrm{V} 0-\mathrm{KO}$ mice suggesting that all V0 subpopulations could contribute to the generation of stage 2 . We suggest that the $\mathrm{VO}_{\mathrm{D}}$ subpopulation of CINs is the main contributor to reciprocal coordination of homonymous axial muscles controlling body rolling during stage 1, while both $\mathrm{V}_{\mathrm{V}}$ and $\mathrm{V} 0_{\mathrm{D}}$ subpopulations of CINs contribute to reciprocal coordination of muscles causing rotation of the hindquarters in relation to the forequarters during stage 2 (Fig. $5 G$ ). Ablation of the corresponding subpopulations of $\mathrm{V} 0$ CINs decreases asymmetry in the activity of homonymous axial muscles causing body movements in opposite directions that results in an increase in duration of movements performed during stage 1 and stage 2 (Fig. 5H, I, stage 2).

\section{$\mathrm{V0}_{\mathrm{D}}$ and $\mathrm{V0}_{\mathrm{C}}$ subpopulations contribute to generation of postural corrections}

In previous studies (Beloozerova et al., 2003; Deliagina et al., 2006), we demonstrated that the postural system stabilizing the dorsal side-up orientation of the trunk consists of two relatively independent subsystems responsible for stabilization of the anterior and posterior parts of the trunk, and driven by somatosensory inputs from the forelimbs and hindlimbs, respectively. To generate appropriate postural corrections in response to lateral tilt of the support surface, each subsystem requires sensory signals from both ipsilateral and contralateral limbs (Deliagina et al., 2006). Our results suggest that inhibitory $\mathrm{V}_{\mathrm{D}} \mathrm{CINs}$, and possibly excitatory $\mathrm{V} 0_{\mathrm{C}}$ neurons, are essential elements of the spinal networks underlying the operation of the postural subsystem stabilizing the orientation of the posterior part of the trunk, while $\mathrm{V} 0_{\mathrm{Glut}}$ neurons do not contribute to the generation of postural corrections.

Corrective movements of the limbs evoked by the platform tilt are caused by a reciprocal coordination of extensor activity in the left and right limbs, with activation of extensors in the limb on the side of the tilt and inactivation of extensors in the opposite limb (Fig. 1H; Beloozerova et al., 2003; Deliagina et al., 2006). We suggest that $\mathrm{V}_{\mathrm{D}} \mathrm{CINs}$ and possibly excitatory $\mathrm{V} 0_{\mathrm{C}}$ neurons mediate sensory input from the limb loaded by the tilt and contribute to the inactivation of extensors in the opposite limb and activation of extensors in the ipsilateral limb, respectively (Fig. 5L). Thus, their ablation causes disinhibition of extensor motor neurons of contralateral limb and a decrease in the activity of extensor motor neurons of ipsilateral limb. This leads to a decrease in the amplitude of the limb corrective movement and results in a decrease in the efficacy of postural corrections (Fig. 5M).

To conclude, the present study reveals the functional role of different subpopulations of V0 neurons in a number of basic motor behaviors. Our data provide a new insight into the organization of the spinal motor circuits and underscore the notion that the left-right coordinating networks may be recruited differentially to secure an appropriate motor execution.

\section{References}

Bannatyne BA, Edgley SA, Hammar I, Jankowska E, Maxwell DJ (2003) Networks of inhibitory and excitatory commissural interneurons mediating crossed reticulospinal actions. Eur J Neurosci 18:2273-2284.

Bannatyne BA, Edgley SA, Hammar I, Jankowska E, Maxwell DJ (2006) Differential projections of excitatory and inhibitory dorsal horn interneurons relaying information from group II muscle afferents in the cat spinal cord. J Neurosci 26:2871-2880.

Batschelet E (1981) Circular statistics in biology. New York: Academic.

Bellardita C, Kiehn O (2015) Phenotypic characterization of speed-associated gait changes in mice reveals modular organization of locomotor networks. Curr Biol 25:1426-1436.

Beloozerova IN, Zelenin PV, Popova LB, Orlovsky GN, Grillner S, Deliagina TG (2003) Postural control in the rabbit maintaining balance on the tilting platform. J Neurophysiol 90:3783-3793.

Berkinblit MB, Deliagina TG, Feldman AG, Gelfand IM, Orlovsky GN (1978) Generation of scratching. I. Activity of spinal interneurons during scratching. J Neurophysiol 41:1040-1057.

Birinyi A, Viszokay K, Wéber I, Kiehn O, Antal M (2003) Synaptic targets of commissural interneurons in the lumbar spinal cord of neonatal rats. J Comp Neurol 461:429-440.

Borgius L, Restrepo CE, Leao RN, Saleh N, Kiehn O (2010) A transgenic mouse line for molecular genetic analysis of excitatory glutamatergic neurons. Mol Cell Neurosci 45:245-257.

Borowska J, Jones CT, Zhang H, Blacklaws J, Goulding M, Zhang Y (2013) Functional subpopulations of V3 interneurons in the mature mouse spinal cord. J Neurosci 33:18553-18565. 
Bouvier J, Caggiano V, Leiras R, Caldeira V, Bellardita C, Balueva K, Fuchs A, Kiehn O (2015) Descending command neurons in the brainstem that halt locomotion. Cell 163:1191-1203.

Buford JA, Zernicke RF, Smith JL (1990) Adaptive control for backward quadrupedal walking. I. Posture and hindlimb kinematics. J Neurophysiol 64:745-755.

Butt SJ, Kiehn O (2003) Functional identification of interneurons responsible for left-right coordination of hindlimbs in mammals. Neuron 38:953963.

Butt SJ, Harris-Warrick RM, Kiehn O (2002) Firing properties of identified interneuron populations in the mammalian hindlimb central pattern generator. J Neurosci 22:9961-9971.

Courtine G, Gerasimenko Y, van den Brand R, Yew A, Musienko P, Zhong H, Song B, Ao Y, Ichiyama RM, Lavrov I, Roy RR, Sofroniew MV, Edgerton VR (2009) Transformation of nonfunctional spinal circuits into functional states after the loss of brain input. Nat Neurosci 12:1333-1342.

Crone SA, Quinlan KA, Zagoraiou L, Droho S, Restrepo CE, Lundfald L, Endo T, Setlak J, Jessell TM, Kiehn O, Sharma K (2008) Genetic ablation of V2a ipsilateral interneurons disrupts left-right locomotor coordination in mammalian spinal cord. Neuron 60:70-83.

Crone SA, Zhong G, Harris-Warrick R, Sharma K (2009) In mice lacking V2a interneurons, gait depends on speed of locomotion. J Neurosci 29:7098-7109.

Deliagina TG (1977) The central pathway of the scratch reflex in cats (in Russian). Neirofiziologia 9:619-621.

Deliagina TG, Feldman AG, Gelfand IM, Orlovsky GN (1975) On the role of central program and afferent inflow in the control of scratching movements in the cat. Brain Res 100:297-313.

Deliagina TG, Orlovsky GN, Pavlova GA (1983) The capacity for generation of rhythmic oscillations is distributed in the lumbosacral spinal cord of the cat. Exp Brain Res 53:81-90.

Deliagina TG, Beloozerova IN, Popova LB, Sirota MG, Swadlow H, Grant G, Orlovsky GN (2000) Role of different sensory inputs for maintenance of body posture in sitting rat and rabbit. Motor Control 4:439-452.

Deliagina TG, Sirota M, Zelenin PV, Orlovsky GN, Beloozerova IN (2006) Interlimb postural coordination in the standing cat. J Physiol 573:211224.

Deliagina TG, Musienko PE, Zelenin PV (2019) Nervous mechanisms of locomotion in different directions. Curr Opin Physiol 8:7-13.

Gosgnach S, Lanuza GM, Butt SJ, Saueressig H, Zhang Y, Velasquez T, Riethmacher D, Callaway EM, Kiehn O, Goulding M (2006) V1 spinal neurons regulate the speed of vertebrate locomotor outputs. Nature 440:215-219.

Goulding M (2009) Circuits controlling vertebrate locomotion: moving in a new direction. Nat Rev Neurosci 10:507-518.

Gray PA (2013) Transcription factors define the neuroanatomical organization of the medullary reticular formation. Front Neuroanat 7:7.

Griener A, Zhang W, Kao H, Wagner C, Gosgnach S (2015) Probing diversity within subpopulations of locomotor-related V0 interneurons. Dev Neurobiol 75:1189-1203.

Haque F, Rancic V, Zhang W, Clugston R, Ballanyi K, Gosgnach S (2018) WT1-Expressing interneurons regulate left-right alternation during mammalian locomotor activity. J Neurosci 38:5666- 5676.

Harrison PJ, Jankowska E, Zytnicki D (1986) Lamina VIII interneurones interposed in crossed reflex pathways in the cat. J Physiol 371:147166.

Jankowska E, Noga BR (1990) Contralaterally projecting lamina VIII interneurones in middle lumbar segments in the cat. Brain Res 535:327-330.

Jankowska E, Cabaj A, Pettersson LG (2005a) How to enhance ipsilateral actions of pyramidal tract neurons. J Neurosci 25:7401-7405.

Jankowska E, Edgley SA, Krutki P, Hammar I (2005b) Functional differentiation and organization of feline midlumbar commissural interneurones. J Physiol 565:645-658.

Jankowska E, Krutki P, Matsuyama K (2005c) Relative contribution of Ia inhibitory interneurones to inhibition of feline contralateral motoneurones evoked via commissural interneurones. J Physiol 568:617-628.

Jessell TM (2000) Neuronal specification in the spinal cord: inductive signals and transcriptional codes. Nat Rev Genet 1:20-29.

Inagaki N, Nagao M, Igeta K, Kawasaki H, Kim JF, Nagai H (2001) Scratching behavior in various strains of mice. Skin Pharmacol Appl Skin Physiol 14:87-96.
Kiehn O (2011) Development and functional organization of spinal locomotor circuits. Curr Opin Neurobiol 21:100-109.

Kiehn O (2016) Decoding the organization of spinal circuits that control locomotion. Nat Rev Neurosci 17:224-238.

Kiehn O, Butt SJ (2003) Physiological, anatomical and genetic identification of CPG neurons in the developing mammalian spinal cord. Prog Neurobiol 70:347-361.

Kuhta PC, Smith JL (1990) Scratch responses in normal cats: hindlimb kinematics and muscle synergies. J Neurophysiol 64:1653-1667.

Lanuza GM, Gosgnach S, Pierani A, Jessell TM, Goulding M (2004) Genetic identification of spinal interneurons that coordinate leftright locomotor activity necessary for walking movements. Neuron 42:375-386.

Lu Y, Inokuchi H, McLachlan EM, Li JS, Higashi H (2001) Correlation between electrophysiology and morphology of three groups of neuron in the dorsal commissural nucleus of lumbosacral spinal cord of mature rats studied in vitro. J Comp Neurol 437:156-169.

Magnus R (1924) Körperstellung. Berlin: Springer.

Matsuyama K, Mori F, Nakajima K, Drew T, Aoki M, Mori S (2004a) Locomotor role of the corticoreticular-reticulospinal-spinal interneuronal system. Prog Brain Res 143:239-249.

Matsuyama K, Nakajima K, Mori F, Aoki M, Mori S (2004b) Lumbar commissural interneurons with reticulospinal inputs in the cat: morphology and discharge patterns during fictive locomotion. J Comp Neurol 474:546-561.

Matsuyama K, Kobayashi S, Aoki M (2006) Projection patterns of lamina VIII commissural neurons in the lumbar spinal cord of the adult cat: an anterograde neural tracing study. Neuroscience 140:203-218.

Moran-Rivard L, Kagawa T, Saueressig H, Gross MK, Burrill J, Goulding M (2001) Evx1 is a postmitotic determinant of v0 interneuron identity in the spinal cord. Neuron 29:385-399.

Musienko PE, Zelenin PV, Lyalka VF, Orlovsky GN, Deliagina TG (2008) Postural performance in decerebrated rabbit. Behav Brain Res 190:124134.

Musienko PE, Zelenin PV, Lyalka VF, Gerasimenko YP, Orlovsky GN, Deliagina TG (2012) Spinal and supraspinal control of the direction of stepping during locomotion. J Neurosci 32:17442-17453.

Nissen UV, Mochida H, Glover JC (2005) Development of projection-specific interneurons and projection neurons in the embryonic mouse and rat spinal cord. J Comp Neurol 483:30-47.

Pierani A, Moran-Rivard L, Sunshine MJ, Littman DR, Goulding M, Jessell TM (2001) Control of interneuron fate in the developing spinal cord by the progenitor homeodomain protein Dbx1. Neuron 29:367-384.

Rabe N, Gezelius H, Vallstedt A, Memic F, Kullander K (2009) Netrin-1dependent spinal interneuron subtypes are required for the formation of left-right alternating locomotor circuitry. J Neurosci 29:15642-15649

Restrepo CE, Lundfald L, Szabó G, Erdélyi F, Zeilhofer HU, Glover JC, Kiehn O (2009) Transmitter-phenotypes of commissural interneurons in the lumbar spinal cord of newborn mice. J Comp Neurol 517:177192.

Ruangkittisakul A, Kottick A, Picardo MCD, Ballanyi K, Del Negro CA (2014) Identification of the pre-Bötzinger complex inspiratory center in calibrated "sandwich" slices from newborn mice with fluorescent Dbx1 interneurons. Physiol Rep 2:e12111.

Sherrington CS (1906) Observations on the scratch-reflex in the spinal dog. J Physiol 34:1-50.

Sherrington CS (1910) Notes of the scratch-reflex of the cat. Exp Physiol 3:213-220.

Stein PS (1983) The vertebrate scratch reflex. Symp Soc Exp Biol 37:383-403.

Stokke MF, Nissen UV, Glover JC, Kiehn O (2002) Projection patterns of commissural interneurons in the lumbar spinal cord of the neonatal rat. J Comp Neurol 446:349-359.

Takeoka A, Vollenweider I, Courtine G, Arber S (2014) Muscle spindle feedback directs locomotor recovery and circuit reorganization after spinal cord injury. Cell 159:1626-1639.

Talpalar AE, Endo T, Löw P, Borgius L, Hägglund M, Dougherty KS, Ryge J, Hnasko TS, Kiehn O (2011) Identification of minimal neuronal networks involved in flexor-extensor alternation in the mammalian spinal cord. Neuron 71:1071-1084. 
Talpalar AE, Bouvier J, Borgius L, Fortin G, Pierani A, Kiehn O (2013) Dualmode operation of neuronal networks involved in left-right alternation. Nature 500:85-88

Vemula MG, Deliagina TG, Zelenin PV (2019) Kinematics of forward and backward locomotion performed in different environmental conditions. J Neurophysiol 122:2142-2155.

Vilensky JA, Cook JA (2000) Do quadrupeds require a change in trunk posture to walk backward? J Biomech 33:911-916.

Wéber I, Veress G, Szucs P, Antal M, Birinyi A (2007) Neurotransmitter systems of commissural interneurons in the lumbar spinal cord of neonatal rats. Brain Res 1178:65-72.

Witschi R, Johansson T, Morscher G, Scheurer L, Deschamps J, Zeilhofer HU (2010) Hoxb8-Cre mice: a tool for brain-sparing
Hoxb8-Cre mice: a tool for brain-sparing conditional gene deletion. Genesis 48:596-602.

Zagoraiou L, Akay T, Martin JF, Brownstone RM, Jessell TM, Miles GB (2009) A cluster of cholinergic premotor interneurons modulates mouse locomotor activity. Neuron 64:645-662.

Zelenin PV, Musienko PE, Gorskii OV, Lyalka VF, Merkulyeva N, Gerasimenko YP, Orlovsky GN, Deliagina TG (2016) Activity of individual spinal neurons during forward and backward locomotion. Soc Neurosci Abstr 42:535.02.

Zhang Y, Narayan S, Geiman E, Lanuza GM, Velasquez T, Shanks B, Akay T, Dyck J, Pearson K, Gosgnach S, Fan C-M, Goulding M (2008) V3 spinal neurons establish a robust and balanced locomotor rhythm during walking. Neuron 60:84-96. 